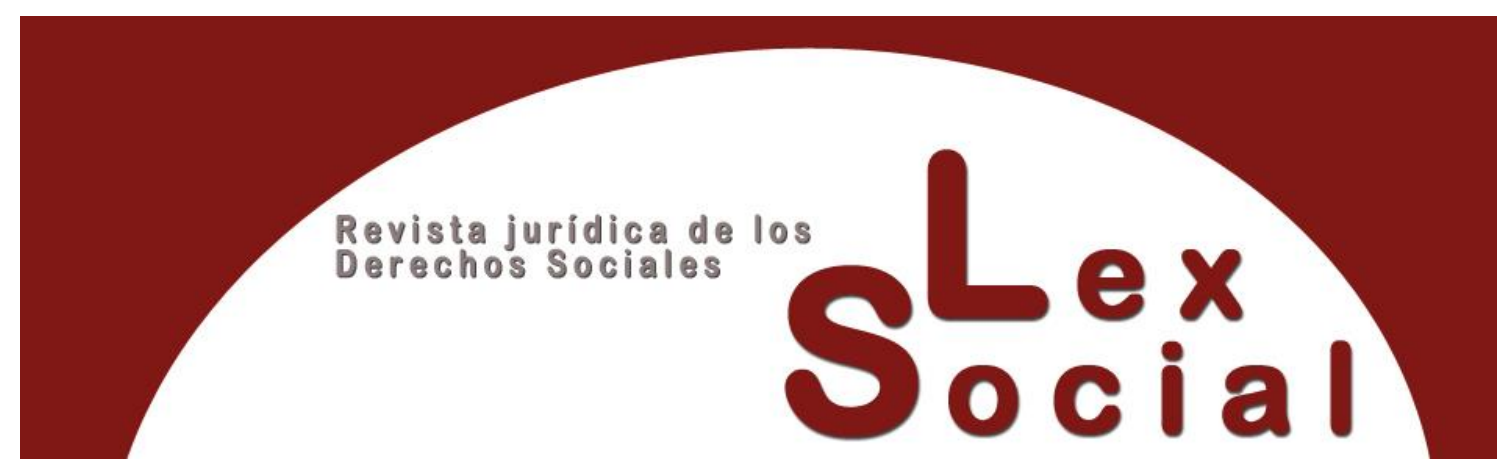

\title{
EL CAPITÁN DEL BUQUE COMO TRABAJADOR DE DIRECCIÓN: CON ESPECIAL ÉNFASIS EN EL DERECHO VENEZOLANO
}

\section{THE SHIP'S CAPTAIN AS A MANAGERIAL EMPLOYEE: WITH SPECIAL FOCUS ON THE VENEZUELAN LAW}

\author{
ERISTER VÁZQUEZ VÁZQUEZ \\ Abogado \\ Universidad Católica Andrés Bello \\ https://orcid.org/0000-0002-4334-3404
}

Cómo citar este trabajo: Vázquez Vázquez, E. (2022). El capitán del buque como trabajador de dirección: con especial énfasis en el derecho venezolano. Lex Social, Revista De Derechos Sociales 12 (1), pp. 468-497. https://doi.org/10.46661/lexsocial.6383

\section{RESUMEN}

La identificación de un capitán como empleado de dirección es una labor que corre usualmente a cargo de la doctrina y la jurisprudencia, la ley escrita rara vez se toma la molestia de aclararlo. La legislación venezolana no identifica de modo expreso al capitán con el empleado de dirección, sin embargo, la jurisprudencia ha tratado varios casos y ha adelantado interesantes motivaciones y conclusiones. Aunque a primera vista su inclusión dentro de la categoría de empleado de dirección parece ser una conclusión obvia, la aplicación de la primacía de la realidad y las variaciones de la jurisprudencia al tratar de precisar los contornos del empleado de dirección aportan elementos de incertidumbre que dan la oportunidad de analizarlo.

Palabras Clave: capitán, empleado de dirección, derecho del trabajo.

\section{(cc) BY-NC-SA}




\begin{abstract}
The identification of a vessel's captain as a managerial employee is usually a matter for doctrine and jurisprudence, the statute law rarely takes the trouble to clarify it. Venezuelan law does not expressly recognize the captain as a managerial employee, however, case law has dealt with several cases and has advanced interesting motivations and conclusions. Although at first sight its inclusion within the category of managerial employee seems to be an obvious conclusion, the application of the primacy of reality and the variations that the jurisprudence has shown trying to draw the boundaries of the managerial employee provides elements of uncertainty that give us the opportunity to analyse it.
\end{abstract}

KEYWORDS: captain, managerial employee, labor law.

SUMARIO

\title{
I. Introducción.
}

II. El trabajador de dirección

1. El tratamiento del empleado de dirección en la jurisprudencia

2. El carácter orientativo de la definición del empleado de dirección en la LOTTT

3. El carácter excepcional del empleado de dirección

4. La primacía de la realidad

5. La capacidad de representación

6. El problema de las decisiones y su entidad

7. Otras variaciones presentes en la jurisprudencia

8. A modo de conclusión previa

III. El Capitán

IV. Consideraciones finales

\section{Introducción}

Ser un empleado de dirección tiene consecuencias relevantes para la legislación del trabajo, las principales, que no únicas, son:

- Puede ser excluido del ámbito de aplicación de la convención colectiva. 
- No disfruta, en principio, de estabilidad ni de inamovilidad laboral y puede ser despedido libremente sin derecho a reenganche, salarios caídos ni indemnización por despido ${ }^{1}$.

- No está sujeto a los límites de la jornada de un trabajador ordinario.

El Tribunal Supremo de Justicia (TSJ) de Venezuela no ha sostenido criterios homogéneos sobre los elementos que lo configuran. Sus salas Político Administrativa (SPA) y de Casación Social (SCS) usan diferentes estándares para calificarlo, más rigurosos en ésta última: No es raro encontrar en una misma Sala, y en poco espacio de tiempo, matices entre decisiones que rara vez tienen explicación y dejan al intérprete dudando si será un simple gazapo o un cambio de criterio. Esta ausencia de homogeneidad junto al elemento fáctico incierto de cada caso, torna difícil la solución de casos complejos.

\section{El trabajador de dirección}

Un trabajador es una persona natural que presta a otra, natural o jurídica, un servicio personal y remunerado bajo subordinación y ajenidad ${ }^{2}$. Existe un tipo especial que la Ley Orgánica del Trabajo, los Trabajadores y las Trabajadoras (LOTTT) ${ }^{3}$ define como aquél que «interviene en la toma de decisiones u orientaciones de la entidad de trabajo, así como el que tiene el carácter de representante del patrono (...) frente a otros trabajadores (...) o terceros, y puede sustituirlo (...), en todo o en parte, en sus funciones». ${ }^{4}$ Esta clase de trabajador es llamado "empleado o trabajador de dirección» ${ }^{5}$.

La derogada Ley Orgánica del Trabajo (LOT) lo definía en su artículo 42 como aquél que: «interviene en la toma de decisiones u orientaciones de la empresa, así como el que tiene el carácter de representante del patrono frente a otros trabajadores o terceros y puede sustituirlo, en todo o en parte, en sus funciones». Su redacción era similar a la actual obviando la engorrosa inserción de géneros masculino y femenino en sustitución del género neutro, y la inclusión del término «entidad de trabajo» ${ }^{6}$.

\footnotetext{
${ }^{1}$ El artículo 87 LOTTT in fine excluye expresamente a los trabajadores de dirección de la protección de la estabilidad laboral al establecer que: « ...los trabajadores y las trabajadoras de dirección, no estarán amparados por la estabilidad prevista en esta ley».

${ }^{2}$ Art. 35 LOTTT.

${ }^{3}$ Gaceta Oficial de la República Bolivariana de Venezuela núm. 6.076 extraordinario de 07.05.2012

${ }^{4}$ Art. 37 LOTTT

${ }^{5}$ Para efectos de este trabajo un empleado es un trabajador donde la labor intelectual predomina sobre la manual sin que deje de ser trabajador en el sentido amplio del término

${ }^{6}$ Este término, suerte de cajón de sastre, está descrito así en el artículo 45 LOTTT:

a) La empresa o unidad de producción de bienes o servicios constituida para realizar una actividad económica de cualquier naturaleza o importancia.

b) El establecimiento o la reunión de medios materiales y de trabajadores y trabajadoras permanentes que laboran en un mismo lugar, en una misma tarea, de cualquier naturaleza o importancia, y que tienen una dirección técnica común.

c) Toda combinación de factores de la producción sin personalidad jurídica propia, ni organización permanente que busca satisfacer necesidades y cuyas operaciones se refieren a un mismo centro de actividad económica.

d) Toda actividad que envuelva la prestación del trabajo en cualquiera condición.

e) Los órganos y entes del Estado prestadores de servicio. Grupo de entidades de trabajo.
} 
De acuerdo al texto de estas normas el empleado de dirección es quien:

(1) Interviene en toma de decisiones u orientaciones de la entidad de trabajo, o

(2) Representa al patrono frente a otros y le sustituye en todo o parte de sus funciones ${ }^{7}$.

La jurisprudencia ha escapado de la limitación textual del artículo —el primer significado de la norma según el art. 4 Código $\mathrm{Civil}^{8}$ venezolano— sin explicaciones satisfactorias.

\section{El tratamiento del empleado de dirección en la jurisprudencia}

Las sentencias sobre el punto son abundantes y poco homogéneas, para ilustrar su tratamiento escojamos una dictada en los inicios del TSJ que a lo largo de los años ha sido base de otras decisiones y opiniones, se trata de la decisión de la SCS n. ${ }^{\circ} 542$ de 18.12.2000 recaída en el caso José Rafael Fernández Alfonzo vs. I.B.M. de Venezuela ${ }^{9}$ la cual, a pesar de sufrir de la extendida forma de perpetrar sentencias donde cohabitan

\footnotetext{
${ }^{7}$ Art. 41 LOTTT

${ }^{8}$ A la Ley debe atribuírsele el sentido que aparece evidente del significado propio de las palabras, según la conexión de ellas entre sí y la intención del legislador.

${ }^{9}$ La definición de empleado de dirección contenida en el artículo 42 de la Ley Orgánica del Trabajo es de naturaleza genérica y los criterios en ella mencionados son meramente orientadores para determinar cuáles trabajadores están incluidos en dicha categoría, dependiendo siempre, la calificación de un empleado como de dirección de la naturaleza real de los servicios prestados, antes que de la denominación que acuerden las partes para el cargo ocupado o que unilateralmente imponga el empleador. Ello en aplicación de los principios de irrenunciabilidad de los derechos del trabajador y de primacía del contrato realidad, contenidos en los artículos 3 y 47 de la Ley Orgánica del Trabajo, respectivamente.

Así, pues, los empleados de dirección conforman una categoría que no disfruta de algunos beneficios que si son percibidos por la mayor parte de los trabajadores, y visto que uno de los principios que informa la Ley Orgánica del Trabajo vigente es el de proporcionar estabilidad al mayor número de trabajadores, debe considerarse que la condición de empleado de dirección es de carácter excepcional y por tanto restringida; en este sentido, la noción de empleado de dirección es aplicable únicamente a los altos ejecutivos o gerentes de las empresas, que participan en lo que se conoce como «las grandes decisiones», es decir, en la planificación de la estrategia de producción, en la selección, contratación, remuneración o movimiento de personal, en la representación de la empresa y en la realización de actos de disposición de su patrimonio. Cuando el legislador se refiere a esta categoría de empleados, indicando que son aquellos que intervienen en la dirección de la empresa, no pretende que sea considerado como empleado de dirección cualquier trabajador que de alguna manera tome o transmita decisiones, pues en el proceso productivo de una empresa gran número de personas intervienen diariamente en la toma de decisiones, muchas de ellas rutinarias y considerar a todo el que tome una resolución o transmite una orden previamente determinada como empleado de dirección llevaría al absurdo de calificar a la gran mayoría de los trabajadores como empleados de dirección, obviando el carácter restringido de tal categoría de trabajadores. Son empleados de dirección sólo quienes intervienen directamente en la toma de decisiones, que determinan el rumbo de la empresa y que pueden representarla u obligarla frente a los demás trabajadores.

Es evidente que por la intervención decisiva en el resultado económico de la empresa o en el cumplimiento de su fines de producción, los empleados de dirección se encuentran de tal manera ligados a la figura del empleador, que llegan a confundirse con él o a sustituirlo en la expresión de voluntad.

Para que un trabajador pueda ser calificado como empleado de dirección, debe quedar claro que éste participa en la toma de decisiones y no sólo ejecuta y realiza los actos administrativos necesarios para cumplir con las órdenes, objetivos y políticas que han sido determinadas previamente por el patrono y los verdaderos empleados de dirección.

Cuando el empleado de dirección representa al patrono frente a terceros o frente a los demás trabajadores, debe entenderse que tal acto de representación es resultado de las apreciaciones y decisiones que él ha tomado o en cuya toma participó, y no que actúa como un mero mandatario; pues, si bien la condición de empleado de dirección implica un mandato del patrono, aún tácito, no necesariamente todo mandato implica que detrás del mismo subyace la condición de empleado de dirección.
} 
imprecisiones y comentarios superfluos con ideas acertadas ${ }^{10}$; contiene elementos constantes del empleado de dirección usados en futuras decisiones, aunque no siempre se consideran todos:

(1) Que su definición en la legislación del trabajo es orientativa, genérica.

(2) Que es una condición excepcional y por lo tanto de interpretación restrictiva;

(3) Que depende de la naturaleza real de los servicios prestados, la cual el patrono debe alegar y probar;

(4) Y que solo son «quienes intervienen directamente en la toma de decisiones, que determinan el rumbo de la empresa y que pueden representarla u obligarla frente a los demás trabajadores». Y esto a su vez requiere que:

(a) Intervengan en las «grandes decisiones», esto es, «... en la planificación de la estrategia de producción, en la selección, contratación, remuneración o movimiento de personal ... en la realización de actos de disposición de su patrimonio» ${ }^{11} ; \mathrm{y} / \mathrm{o}^{12}$

(b) Cuando representan lo hacen respecto a «las apreciaciones y decisiones que él ha tomado o en cuya toma participó, y no que actúa como un mero mandatario», en palabras de la sentencia.

\section{El carácter orientativo de la definición del empleado de dirección en la LOTTT}

Considerar que la definición es orientativa causa disímiles criterios. Todo análisis de una norma implica el aporte particular del intérprete, es inevitable, se dota de flexibilidad a la ley y permite adecuarla a las condiciones y situaciones no previstas por quien dictó la norma, pero cuando el máximo órgano judicial manifiesta su voluntad de no guiarse por ella porque «los criterios en ella mencionados son meramente orientadores para determinar cuáles trabajadores están incluidos en dicha categoría», agrega un nivel de variación elevado, no es lo mismo analizar, precisar y profundizar los contornos de los

\footnotetext{
${ }^{10}$ Según qué parte de la citada sentencia se lea los empleados de dirección o bien solo «intervienen en la dirección de la empresa» o bien «intervienen directamente en la toma de decisiones que determinan el rumbo de la empresa y que pueden representarla u obligarla frente a los demás trabajadores». Así genera la duda sobre si debe representar y decidir o solo decidir, una sola letra una sola conjunción y cambia el sentido de la motivación. No es raro encontrar sentencias que requieren una o ambas condiciones a la vez dependiendo del arbitrio del juez de turno. En otro pasaje de la sentencia hay otra imprecisión: «la condición de empleado de dirección implica un mandato del patrono, aún tácito», como no todo mandato implica representación, si la implicare habría una interpretación circular y absurda en la sentencia pues ha tratado la representación como un elemento de análisis que determinaría la condición de empleado de dirección al mismo tiempo que la trataría como consecuencia de serlo. Un evento no puede ser su causa y su consecuencia a la vez, es posible que un evento dado sea, para un caso, su causa, y para otro caso diferente una consecuencia. Podría argüirse que habría una representación derivada de doble título, pero esto lleva a que la representación cause el carácter directivo y este a su vez cause la representación en un círculo interminable haciendo dudar de la utilidad de la representación en el análisis. Como no es claro el tipo de mandato al que quiso referirse el TSJ, solo podemos hablar de imprecisión y no de contradicción. Sea cual sea el criterio del juez sobre la representación y la participación seguro encontrará una sentencia del TSJ donde apoyarse.

${ }^{11}$ Sentencias de la SCS n. ${ }^{\circ} 971$ de 5.08.2011 y n. ${ }^{\circ} 290$ de 26.03.2010 (BOD), que reiteran criterio de las

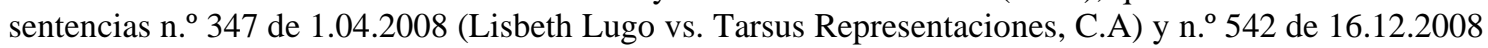
(Peña vs. Recuperaciones Venamerica RVA, C.A)

${ }^{12}$ Utilizamos las conjunciones y/o deliberadamente para recoger en forma sucinta el feroz enfrentamiento de la jurisprudencia con la precisión.
} 
elementos dados por el legislador que agregar otros nuevos, la fina línea divisoria entre la función legislativa y la judicial se difumina, quizá pueda verse como un legítimo ejercicio de la función interpretativa pero la intensidad, frecuencia y alcance de su ejercicio puede tener efectos importantes, es una cuestión de dosis, no es lo mismo caer de una silla que caer de un primer piso, en ambos casos se cae pero los efectos son algo divergentes. Esta libertad ha dado paso a la imprecisión y no la certeza y predictibilidad de criterios que crean la seguridad jurídica. La incerteza infecta tanto la premisa mayor del silogismo - supuesto de la norma - como en la premisa menor - hechos - que es libremente apreciada por el poder judicial. La apreciación de las pruebas y de los hechos pertinentes es competencia típica del juez pero en estos casos los sesgos cognitivos suelen tener efectos profundos en el establecimiento de los hechos limitando, cuando no eliminando, el examen congruente, completo y objetivo de lo controvertido y sus probanzas.

\section{El carácter excepcional del empleado de dirección}

Es razonable aplicar una interpretación restrictiva en los casos de organizaciones patronales típicas que atienden a una forma piramidal, donde el vértice representa el mayor poder de decisión y representación los cuales van diluyéndose a medida que los cargos se van aproximando a la base de la pirámide siendo presumible que más populada estará la base que su vértice y por lo tanto hay mayor probabilidad de pertenecer a la base, pero no todas las organizaciones son así, y ante nuevos escenarios se requerirán nuevas herramientas, o al menos usarlas de distinta manera. Piénsese en organizaciones de economía colaborativa, o en la holocracia donde la organización tiene distribuidas de modo horizontal la autoridad y toma de decisiones, o en microempresas familiares donde todos parecen tener poder de decidir al mismo tiempo que obedecen diluyendo cualquier división de jerarquía; los casos pueden ser innumerables.

\section{La primacía de la realidad}

Las formas ceden ante la realidad, sean impuestas deliberadamente o no, sean originarias o adquiridas. El principio obliga a analizar cada caso concreto para determinar si el trabajador ejerce o no las funciones propias de un empleado de dirección más allá de su apariencia, de su nomen iuris. Se pueden dar casos donde, sin ser exhaustivos: (a) un trabajador desempeñe las funciones de un capitán, con o sin designación formal en el cargo por parte del patrono, sin tener ni la titulación adecuada bajo los criterios de las autoridades acuáticas; o (b) tenga el cargo de capitán asignado y la titulación apropiada, pero desempeñe funciones distintas a las del capitán.

Críticas se han vertido cuando la SCS hace prevalecer la realidad de la prestación de servicio ignorando la ilegalidad del desempeño del cargo por no haber satisfecho los requerimientos y procedimientos de las autoridades acuáticas para gobernar una embarcación. Se teme que pueda usarse como puerta de entrada ilegítima al cargo de capitán. El punto es interesante, volveremos más tarde sobre él. El peso que se la ha dado a los derechos sociales derivados de la relación de trabajo ha hecho doblegar a otros de menor carácter social, esto no significa que los derechos de los trabajadores sean 
absolutos. Ningún derecho lo es. El orden jurídico se basa en la interrelación armónica de múltiples derechos, en su coherencia intrínseca.

No puede obviarse que la aplicación de la primacía de la realidad está infectada por marcados sesgos cognitivos. Ejemplo de ello en casos de declaración de simulación es la fijación de astronómicas compensaciones en favor de los trabajadores demandantes asumiendo que han sido defraudados por el empleador sin analizar la causa simulandi, no siempre el motivo y fin es disminuir las percepciones del trabajador sino evadir el régimen de estabilidad, los aportes al sistema de seguridad social o el engorroso sistema de prestaciones, por mencionar las víctimas habituales, por lo que no siempre hay una real disminución de percepciones salariales de allí que se obtengan compensaciones que multiplican lo percibido por otros trabajadores por el mismo trabajo en la misma empresa o zona geográfica. Nadie parece detenerse a analizar que el ilícito o el incumplimiento, per se, no dan derecho a indemnización, nadie se detiene a analizar si hubo daño o no, de este modo la jurisprudencia crea una superclase de trabajadores desmesuradamente pagados que rompen el principio de igual trabajo igual salario y crean de facto una pena pecuniaria en cabeza del patrono. El sesgo cognitivo pasa por dar por sentado que cuando hay evasión de una norma que impone una obligación al patrono es éste su autor y el trabajador la víctima que ha sufrido un daño. Preñados de estos sesgos nunca analizan la autoría de la simulación, ni el motivo de ella, ni hacen la operación ideal de sustraer el ilícito, el incumplimiento, de la cadena de eventos y analizar cuál sería la situación razonable y esperable del trabajador si la norma no se hubiera vulnerado para darle esa condición, no una mejor, no una peor, sino la exacta medida ideal de ella. En el caso que nos ocupa, si el tribunal detecta simulación en quien desempeña el gobierno de la nave lo normal es esperar que interprete que el trabajador es la víctima no culpable y el patrono el autor doloso.

\section{La capacidad de representación}

La LOTTT no limita la representación del directivo a aquellas decisiones que él ha tomado o en las que ha participado, puede pertenecer a una junta directiva, participar en sus decisiones, y representarla en decisiones que han tomado otros órganos distintos de la junta, no por ello pierde la condición de empleado de dirección, pero la jurisprudencia insiste en distinguir el mandatario del empleado de dirección, ciertamente son figuras distintas aunque nada impide que en una misma persona coincidan ambas a la vez. La forma en que suele diferenciarlos es sostener que éste toma decisiones y representa, mientras que aquél representa y actúa los designios del mandante, de ello concluye que el empleado de dirección representa como «resultado de las apreciaciones y decisiones que él ha tomado o en cuya toma participó», de lo contrario sería un mandatario simple. No compartimos este criterio, además es de poca o nula utilidad pues para el artículo 41 LOTTT representa al patrono «toda persona natural que en nombre y por cuenta de éste ejerza funciones jerárquicas de dirección o administración», de tal modo que siempre que ejerza funciones jerárquicas directivas representará y no solo en aquellas decisiones en las que participe. Será en muchos casos incierto diferenciar cuándo tal representación sea consecuencia exclusiva del carácter directivo o tenga otra causa, por ejemplo, a los 
directivos se les suele otorgar poderes o mandatos como modo de facilitar la acreditación documental de sus facultades ante terceros no como título constitutivo de esas facultades, es decir, el documento que contiene el mandato no es el título del mandato pero en la práctica es común ver como confunden el título con el documento y de allí la causa con la consecuencia. En España. por ejemplo, el tema del apoderamiento como elemento diferenciador de un alto directivo fue considerado y desechado tiempo atrás pues es un elemento instrumental de la función del empleado, no un elemento constitutivo de ella ${ }^{13}$. El esfuerzo por adjuntar la representación a la toma de decisiones ha sido soporte de criterios donde analizan y exigen que en un persona coincidan ambos, pero aunque puede tenerse prima facie la impresión de que ha sido adecuado el razonamiento, resultará difícil extraer un principio válido para otros casos pues: (i) rara vez se analiza el título del cual deriva la representación; (ii) no hay motivación adecuada, cuando no inexistente, sobre el porqué representación y participación han de ir juntas si el artículo 35 LOTTT no lo requiere, y (iii) tampoco se encuentra desarrollo de una especial característica que el legislador pide para esa representación y que consiste en que sea de tal entidad que pueda sustituir al patrono en todo o parte de sus funciones.

\section{El problema de las decisiones y su entidad}

Es difícil discernir el peso específico que debe tener una persona en las grandes decisiones para considerarla personal de dirección, el acto de decidir tiene un proceso formativo complejo que no se puede confundir con la decisión — su resultado - es una serie de piezas que se articulan para formar la voluntad final. Una persona puede aportar piezas al proceso formativo de la decisión sin que formalmente decida y su peso real puede convertirle en un personal que participa en decisiones relevantes aunque formalmente no aparezca facultado, del mismo modo es habitual encontrar integrantes de órganos directivos colegiados con peso relevante en las decisiones de tales órganos pero que considerados individualmente carecen de poder de decisión y representación, no obstante sí los posee el órgano al cual pertenece y que ellos integran como pieza necesaria, esencial.

Ni la doctrina ni la jurisprudencia dan una definición precisa de lo que es un gran decisión, su vago contorno está atenido a la apreciación que el juez haga del caso particular, y tampoco ha tenido remilgos la SCS para ignorar este requisito de su propia implantación. En la sentencia de la SCS en el caso Edgar Ricardo Santos Molina vs. CANTV ${ }^{14}$ del 01.08.2016, solo hablan de la inserción del cargo en «la estructura organizacional de la empresa, que le da un rango de representante del patrono frente a trabajadores y terceros», omitiendo toda consideración a las decisiones grandes o las que él mismo representa, como si la inserción en la estructura organizacional supusiera que interviene «en la toma de decisiones u orientaciones» del patrono sin molestarse en valorarlas.

\footnotetext{
${ }^{13}$ MARTÍNEZ MORENO, Carolina, "El Trabajo de Alta Dirección: Evolución Histórica y Fuentes de Regulación”, Revista Española de Derecho del Trabajo, N. ${ }^{\circ}$ 125, Civitas, 2005, pp 827-854

14 ...el cargo desempeñado por el demandante, es de aquellos insertos dentro de la estructura organizacional de la empresa, que le da un rango de representante del patrono frente a trabajadores y terceros, de lo cual se concluye que efectivamente el puesto de trabajo desempeñado es un cargo de dirección
} 
En todo caso es difícil considerar que quien tome una gran decisión — si supiéramos con exactitud lo que ello significa - no represente, no solo por orden del artículo 41 LOTTT, sino porque arrojaría un resultado poco razonable: que quien tome decisiones sobre, por ejemplo, qué, cuánto y cómo se produce, pero no represente, sea un trabajador ordinario por carecer de representación.

\section{Otras variaciones presentes en la jurisprudencia}

Hay diferencia de rigor entre las diferentes Salas del TSJ. La SPA en la sentencia N. 315 de 25.03.2015 (caso Orlando Antonio Parejo vs. Construcciones Rimoca) consideró empleado de dirección a un Supervisor Eléctrico pues «A [su] cargo están subordinados 4 obreros que tiene como función estar presente en todas las actividades del proyecto (si llegan a incumplir los [puede] sancionar)», de manera que en razón de las funciones reconocidas por el trabajador «ejercía un cargo considerado como de dirección», este criterio también lo ha manifestado en las sentencias N. ${ }^{\circ} 96$ del 19.02.2015 (Rosa V. Fernández S. vs. Banco Bicentenario Banco Universal, C.A) y N. ${ }^{\circ}$ de 27.02.2015 (Juan Carlos Arzola Monsalve vs. CABEL) ${ }^{15}$. En dichos casos la capacidad de representación y supervisión establecida en los contratos de trabajo fue suficiente para atribuirles tales condiciones de trabajadores de dirección y ser desechada su inamovilidad, poco o ningún peso parece darle la SPA a la participación en decisiones cuando detecta facultades de representar aunque esa representación no se refiera a sus propias decisiones. La Sala Constitucional $(\mathrm{SC})^{16}$ no presenta unos criterios tan laxos, es más cercana a la SCS, sostiene la necesidad de considerar al trabajador de dirección como excepcional por ser quien participa en la toma de directrices fundamentales de la unidad que dirige entendiendo por tales aquellas que se refieren a: su objetivo social, sus políticas de producción o mercadeo, la selección, contratación, remuneración o movimiento de personal; así como el que tiene el carácter de representante del patrono frente a otros trabajadores o terceros y puede sustituirlo, en todo o en parte, en sus funciones.

También es posible encontrar sentencias curiosas como la núm. 122 del 05.04.2013 de la SCS:

Para que un trabajador pueda ser calificado de dirección, es necesario que cumpla con una cualquiera de estas tres condiciones, a saber, que intervenga en las decisiones u orientaciones de la empresa; o que tenga el carácter de representante del patrono ante

\footnotetext{
${ }^{15}$ La Sala dijo que las funciones inherentes al cargo de dirección Supervisor de Mantenimiento eran: «realizar solicitudes de repuestos y herramientas para suministrárselo a los mecánicos y éstos pudieran cumplir con sus tareas de manera adecuada, velar por las mejoras en métodos de reparaciones en equipos de planta por parte del personal mecánico, manejo de sobretiempos, vacaciones y permisos y todo concerniente con los mecánicos de mantenimiento preventivo, manejo de proveedores, planificación de trabajos en planta, estudiar mejoras para equipos de planta, detección y análisis de fallas, seguimiento a tareas realizadas, evaluación de los mecánicos y solicitudes de adiestramiento y detección del mismo, solicitudes de inclusión a stock de repuestos nuevos y evaluación de cantidad de stock en almacén, recepción de necesidades que corresponden a mantenimiento de otros departamentos» (resaltado de la Sala). ${ }^{16}$ Sentencia n. ${ }^{\circ} 678$ del 14.08.2017
} 
otros trabajadores o terceros; o que pueda sustituir, en todo o en parte, al patrono sin importar la denominación del cargo ${ }^{17}$.

Este es un razonamiento similar al sostenido por la misma Sala en la sentencia del 13.12.2012 del caso Eduardo Galán vs. PDVSA GAS. Lo curioso está en que crean un tercer elemento independiente: «sustituir, en todo o en parte, al patrono sin importar la denominación del cargo» cuando, como se ha anotado, la LOTTT no contempla esto como elemento independiente sino como una característica necesaria de la representación.

\section{A modo de conclusión previa}

La jurisprudencia ha sido inconsistente. Esto es un síntoma, a parte de las propias falencias del TSJ, del forcejeo que existe entre las fronteras internas del derecho del trabajo que, a semejanza de placas tectónicas, se mantienen en constante fricción y de cuando en cuando producen movimientos inesperados, e ilógicos. No puede dejarse de lado que el derecho del trabajo enfrenta varios retos $^{18}$, ya no es objeto del interés que antaño despertaba al punto que hay quien cuestiona su utilidad o validez como disciplina autónoma, por otra parte su objeto y sus límites son debatidos, ¿debe centrarse solo en la protección del trabajador? ¿Debe ser instrumento de política económica y fomentar la riqueza general de la sociedad? ¿Cómo equilibra la seguridad que anhelan los trabajadores con la flexibilidad que buscan los empleadores? Es un tema convulso que podrá redibujar los límites externos del derecho del trabajo y cambiar la legislación y la visión de los jueces, mientras eso ocurre ha de buscar proteger al débil que se encuentre dentro de su ámbito personal de aplicación pero no todos tienen el mismo grado de debilidad jurídica, por lo tanto no merecen igual regulación pues no ha de tratarse del mismo modo lo que no es igual, así que la diatriba se ceba por ahora sobre cuales categorías se protegen más que otras, y entre las disposiciones vagas del legislador, la ausencia de sentido crítico en la doctrina y la inconsistencia y atrevimiento de la jurisprudencia, tenemos unos desarrollos y explicaciones que a fuerza de generalidad puede caber en ellas cualquier cosa que el intérprete pueda colocar con un mínimo de argumentación razonable y seguro encontrará una sentencia en la cual apoyarse.

Quizá el camino más racional sea retornar a la simple redacción legislativa y entender que la representación es un elemento autónomo que no está, ni tiene porque estar, vinculado a las grandes decisiones que el mismo trabajador tome, sino a que esa representación sea de una entidad tal que le permita sustituir al patrono en todo o en parte frente a sus propios trabajadores, poco importa que esa representación derive de un mandato - pues puede contener tanto facultades formidables como inocuas-, o de otra fuente pues el legislador no restringe, ni veo motivo para que restrinja, el origen de esa facultad de representar y sustituir. Dada tal facultad, con independencia de su causa o

17 Ver texto íntegro de sentencia en: http://www.tsj.gov.ve/decisiones/scs/Abril/0122-5413-2013-101084.html

18 VRANKEN, Martin. "Death of Labor Law? Comparative Perspectives", Melbourne University Press. 2009, p ix. 
título, podrá considerarse trabajador de dirección. Entonces, si seguimos y desarrollamos la redacción de la LOTTT resulta que:

(1) Cuando el trabajador participara en $«$ grandes» ${ }^{19}$ decisiones no habría que analizar si representa, pues ese solo elemento bastaría para calificarlo como de dirección.

(a) Como decide representa, por orden del art. 41 LOTTT.

(2) Dado que siempre representa, la representación no causada por ese participar en grandes decisiones, solo podría referirse a:

(a) Las decisiones de otros, pues si decide representará.

(b) Las decisiones en las que participe no sean «grandes» si es que sabemos con exactitud lo que eso significa. De este modo un empleado de dirección podría también ser aquél que representa en ejercicio de sus propias — ¿pequeñas o medianas?decisiones sin participar en decisiones grandes, porque de ser grandes esas decisiones en las cuales representa siempre volveríamos al punto inicial.

(c) Y en cualquier caso la representación debe ser de una entidad tal que le permita sustituir en todo o en parte al patrono, y la variación en intensidad y amplitud de esa sustitución permitirá dilucidar si es o no empleado de dirección. Sin olvidar que ejercer un mandato simple no es incompatible, ni anula las facultades de dirección ni la capacidad de representación nacida de otro título distinto a ese mandato simple.

\section{El Capitán}

Antes de entrar en el desarrollo de este punto conviene detenerse brevemente a analizar al Capitán desde, principalmente, el Convenio Internacional sobre Normas de Formación, Titulación y Guardia para la Gente de Mar (STCW 1978) ${ }^{20}$, así como por la Ley Aprobatoria del Convenio Internacional Sobre Normas de Formación, Titulación y Guardia para la Gente de Mar de 1978, en su forma enmendada de 1995 (STCW 78/95) ${ }^{21}$ y la legislación acuática venezolana. Dado que el Capitán es el responsable de que la expedición llegue a buen término se le conceden poderes de mando sobre la dotación y de dirección técnica sobre el buque, pero para ello de modo previo debe haber acreditado apropiados conocimientos y cualificaciones, y para ello se regula la expedición de sus títulos.

Al hacer al capitán responsable del buque se le dan, necesariamente, varias obligaciones o deberes de orden técnico, comercial, laboral, público así como naturalmente las

\footnotetext{
19 Dada la brevedad de este artículo omitiremos extendernos sobre lo que puede o no ser una "gran decisión", y su validez como elemento diferenciador entre un empleado ordinario y uno de dirección. Así que para efectos de este trabajo daremos por bueno que un trabajador deba participar en "grandes" decisiones y esto es algo terriblemente casuístico que solo puede apreciarse en cada caso concreto, ciertas sentencias son tan estrictas al desarrollar el punto que parecería imposible que una empresa transnacional pudiera tener verdaderos empleados de dirección fuera de su sede central.

${ }^{20}$ Ratificado por Ley Aprobatoria publicada en la Gaceta Oficial de la República de Venezuela No 3.878 Extraordinario de 15 de agosto de 1986.

${ }^{21}$ Gaceta Oficial de la República Bolivariana de Venezuela, N. 5.752 Extraordinario de 03 de enero de 2005.
} 
referidas al mando náutico de la embarcación, entre ellos, que no todos, resaltan: (i) cuidar del buen estado de navegabilidad del buque conforme a la legislación y a la buena práctica marítima: (ii) prevenir abordajes; (iii) aplicar medidas de seguridad exigidas por la legislación y por la buena práctica marinera, siempre con vista en las circunstancias; (iv) mantener guardia de navegación segura; (v) prestar auxilio al otro buque en caso de abordaje salvo que ello pusiera en riesgo su propia nave; (vi) si el buque estuviera en riesgo adoptar las medidas posibles para el salvamento de los pasajeros, su tripulación y de la documentación del buque; (vii) llevar el Diario de Navegación anotando toda circunstancia referida al buque (por ejemplo averías), a la carga, a la navegación (como las condiciones meteorológicas, rumbo, fuerza de las máquinas), actos sucedidos a bordo con trascendencia jurídica; (viii) redactar protestas de mar; (ix) ejecutar, cuando corresponda, actos y labores propios del registro civil.

Las referidas obligaciones solo pueden ser cumplimentadas por un marino cualificado, competente y prudente. Por eso la formación profesional del capitán tiene importancia capital y solo puede acceder a la titulación si satisface, al menos, los requisitos mínimos establecidos en el STCW vigente al momento de su exigencia. Los títulos son la prueba escrita por excelencia del cumplimiento de tales requisitos. La Ley de Marinas y Actividades Conexas (LMAC) venezolana exige además que han de poseer poseer título de educación superior expedido en las universidades de educación superior náutica, inscritas en el Instituto Nacional de los Espacios Acuáticos y realizar prácticas de navegación supervisadas, por lo menos durante doce meses. Las altas responsabilidades que posee sobre las personas bajo su jefatura en esa comunidad flotante que forma la dotación de un buque, así como las responsabilidades por las cargas, pertrechos, puertos y otros navegantes obligan al capitán a obtener, mantener y desarrollar capacidades técnicas y virtudes necesarias para responder a las exigencias del cargo. La única manera de que ejecute eficazmente sus labores es confiriéndole facultades y poderes, a veces formidables, raros de encontrar conjuntados en otra figura jurídica, sin ellos no sería posible ser el jefe que ha de ser. Sobre ello volveremos adelante, antes conviene hacer la precisión de que en el ámbito laboral la denominación de capitán establecida en la LOTTT no equivale al capitán de altura, se refiere a quien gobierna un buque, remolcador o lancha.

La SCS, en el caso Freddy Caldera vs. Tucker Energy Services de Venezuela C. A. ${ }^{22}$, equiparó el patrón de lancha de nuestra legislación marítima con el capitán regulado por

\footnotetext{
${ }^{22}$ Sentencia del 10.11.2005 num. 1593, ratificada por sentencia de la Sala Constitucional del 09.06.2006: ...llevaba el registro sobre el control diario de dicha embarcación referente al tipo de operaciones realizadas a bordo; estado de los equipos, aceites, filtros, combustibles; tiempo recorrido; horario de salida y llegada; datos concernientes a la tripulación; observaciones geográficas y meteorológicas; sucesos importantes del viaje y cualquier otra novedad que se presentaba durante su travesía, los cuales se encuentran suscritos por el ciudadano Freddy Caldera, en su carácter de Capitán.

Asimismo, de las declaraciones rendidas por el actor en la audiencia celebrada por ante esta Sala de Casación Social, quedó evidenciado que él era quien se encargaba del pilotaje de la embarcación durante su travesía, lo cual trae como consecuencia que en sus funciones recayera la responsabilidad de salvaguardar, entre otras, la nave, los equipos, el cargamento y la tripulación.

De lo precedentemente expuesto, extrae la Sala que el ciudadano Freddy Antonio Caldera efectivamente reportaba a la empresa todos los acontecimientos diarios suscitados dentro de la embarcación y que además
} 
la LOTTT en vista de la real naturaleza de las funciones prestadas por el trabajador. Siguiendo esta misma línea argumental la SCS en sentencia n. ${ }^{\circ} 1593$ de 23.11.2011 (caso Juvenal Antonio Medina vs. Transmarveca ${ }^{23}$, consideró que el patrón de lancha en este caso no gobernaba la nave y no podía equipararse al capitán de la legislación laboral. Para la SCS lo relevante siempre es la verdadera naturaleza de la labor prestada aún cuando carezca: (i) de la preparación, certificación o titulación adecuada, y (ii) de la asignación formal del cargo por el patrono o armador; por lo tanto calificará como capitán, solo para efectos del derecho del trabajo, a quien ostente el gobierno de la nave. No debe entenderse que vulnere la competencia de las autoridades que regulan el transporte acuático, ni en el levantamiento del deber de obtener y mantener al día los títulos y permisos suficientes para el cargo que desempeñarán en una embarcación ${ }^{24}$.

sobre él recaían responsabilidades de tal envergadura, que no hacen absurdo pensar que en realidad éste sí ostentaba el cargo de Capitán, ejerciendo las funciones inherentes a dicho cargo, y por tanto por mandato expreso de la Ley Especial en materia marítima, representaba la máxima autoridad a bordo, estando todas las personas bajo su supervisión.

Siendo ello así, la labor del accionante no puede catalogarse como la de un trabajador ordinario como lo indica la Juzgadora de Alzada, sino como un trabajador de dirección y de confianza que representaba al patrono frente a la tripulación y frente a terceros, al ser considerado la máxima autoridad dentro de la embarcación, por lo que al haber quedado comprobada la naturaleza de las labores que tenía el trabajador en la empresa en aplicación del principio de primacía de la realidad de los hechos sobre las formas o apariencias, resulta forzoso para la Sala declarar procedente la presente denuncia, por falta de aplicación del artículo 51 de la Ley Orgánica del Trabajo y falsa aplicación de la cláusula tercera de la Convención Colectiva Petrolera, en concordancia con lo establecido en el artículo 509 eiusdem, en virtud a que el actor se encuentra exceptuado del ámbito de aplicación de dicha Convención.

${ }^{23}$ (...) siendo que las funciones del demandante eran las de un patrón de lancha, (como se demuestra tanto de las documentales como de la cédula marina en copias simples, y certificada por el Instituto Nacional de los Espacios Acuáticos (INEA), y de los propios recibos de pagos como de la contestación de la demanda), el demandante no intervenía en la toma de decisiones de la empresa, como tampoco podía sustituir al patrono frente a los trabajadores, ni tampoco tenía conocimientos personales de secretos industriales del patrono, por lo que mal podría clasificarse al ciudadano Juvenal Antonio Medina, como un empleado catalogado en el artículo 42 del capítulo IV «De las Personas en el Derecho del Trabajo» de la Ley Orgánica del Trabajo, en virtud de que el alcance y contenido de la norma citada establece de manera explícita que para poder catalogar un trabajador con condiciones como empleado de dirección o trabajador de confianza, se debe fundamentar en la realidad de los hechos, establece el artículo 47 de la Ley Orgánica del Trabajo que «La calificación de un trabajador como de dirección, confianza inspección o vigilancia, dependerá de la naturaleza real de los servicios prestados, independientemente de la denominación que haya sido convenida por las partes o de la que unilateralmente hubiese establecido el patrono».

Así las cosas, las reflexiones antes expuestas adquieren pleno asidero conforme al principio constitucional de la irrenunciabilidad de los derechos laborales, por cuanto no puede pretenderse que un trabajador decline a ciertos beneficios que son excluidos por la legislación laboral para los empleados de dirección y trabajadores de confianza, cuando la realidad de los hechos, como ocurre en el presente asunto, es que las funciones desempeñadas por el accionante de autos, no ostenta la condición como tal, y en aplicación del artículo 47 eiusdem y tomando en cuenta las declaraciones libelares y los términos como fue contestada la demandada, constata este Superior Tribunal que el trabajador era el encargado de traslado de pasajeros y carga a las diferentes gabarras de PDVSA y sólo es un patrón y que además según la declaración de parte del mismo demandante, él efectuaba el mantenimiento de la lancha, su reparación y manejo debido a que fue instruido por un Canadiense para el manejo de la Lancha Preven I; y no un capitán que es la máxima autoridad en una embarcación; todo lo cual conlleva a la convicción de esta Alzada, que la labor desempeñada por el trabajador fue un simple trabajador o trabajador común dentro de la clasificación ordinaria de un trabajador, en consecuencia, no es un empleado de dirección ni de confianza...

${ }^{24}$ Artículo 160 LMAC. El Instituto Nacional de los Espacios Acuáticos expedirá los títulos, licencias, refrendos y certificaciones de las competencias de la gente de mar, de acuerdo con las normas nacionales e internacionales que rigen la materia, sin perjuicio de lo establecido en las leyes que rigen la materia. 
La LOTTT en su artículo 245 prevé que el trabajo en la navegación esté regulado, como ya hemos esbozado también por la Ley de Marinas y Actividades Conexas (LMAC) y los tratados internacionales suscritos y ratificados en materia acuática. También debe ajustarse a los requerimientos de otras normas, pues aunque la LOTTT no las mencione tampoco las deroga, como la Ley Aprobatoria del Convenio Internacional Sobre Normas de Formación, Titulación y Guardia para la Gente de Mar de 1978, en su forma enmendada de 1995 (STCW 78/95) ${ }^{25}$, o algunos reglamentos antiguos ${ }^{26}$.

Es claro que el capitán debe obtener y mantener las licencias, permisos, títulos y certificados que la ley prescriba ${ }^{27}$, de no ser así no debe navegar y el zarpe del buque puede ser prohibido ${ }^{28}$; pero si a pesar de ello realiza las funciones del capitán se le ha de

El Estado, a través de la Autoridad Acuática, reconocerá los grados, títulos y certificados de competencia de la gente de mar que otorguen y expidan las universidades nacionales de acuerdo con los convenios internacionales y las leyes que rijan la materia.

Artículo 279 LMAC. Los títulos de Marina Mercante facultan para desempeñar a bordo, las siguientes funciones;

1 Capitán de Altura: en la especialidad de navegación: para ejercer el mando de buques de cualquier clase y arqueo, en todos los mares.....

Artículo 280 LMAC. Los títulos de Marina Mercante facultan para desempeñar a bordo, las siguientes funciones:

1 Capitán Costanero: para ejercer el mando de buques cuyo arqueo bruto esté comprendido entre quinientas unidades (500 AB) y tres mil unidades (3.000 AB), entre las zonas comprendidas entre los $7^{\circ} \mathrm{y}$ $19^{\circ}$ latitud Norte y $\operatorname{los} 58^{\circ}$ y $85^{\circ}$ longitud Oeste y para montar guardia en buques que hagan esta misma navegación.

2 Patrón de Primera: para ejercer el mando en buques cuyo arqueo bruto sea igual o inferior a quinientas unidades (500 AB) que naveguen entre las zonas comprendidas entre los $7^{\circ}$ y $13^{\circ} 30^{\prime \prime \prime}$ latitud Norte y $\operatorname{los} 60^{\circ}$ y $72^{\circ}$ longitud Oeste, con excepción de buques de pasajeros que naveguen fuera de las aguas interiores y para desempeñarse como oficial de navegación en buques cuyo arqueo bruto sea igual o menor a tres mil unidades (3.000 AB) que naveguen dentro de la zona señalada.

3 Patrón de Segunda: para desempeñarse como oficial de navegación en buques cuyo arqueo bruto sea igual o menor a ciento cincuenta unidades de Arqueo Bruto (150 AB) en aguas jurisdiccionales de la República. Para ejercer el mando de buques cuyo arqueo bruto sea igual o menor de cincuenta unidades (50 $\mathrm{AB})$ de arqueo bruto en una circunscripción Acuática, o buques pesqueros y de transporte de productos agrícolas menores de veinticuatro metros (24 mts.) de eslora, en una circunscripción acuática.

4 Patrón Artesanal: para ejercer el mando de buques de tipo artesanal o primitivas, así como aquellas propias de las comunidades indígenas, campesinas y de pescadores ribereños, menores de veinticuatro metros (24 mts.) de eslora, en una circunscripción Acuática específica....

Artículo 250 LMC. El Instituto Nacional de los Espacios Acuáticos, expedirá los títulos, licencias y permisos, así como los refrendos y dispensas de la Gente de Mar a que se refiere esta Ley, previo cumplimiento de los requisitos exigidos en el reglamento respectivo.

Artículo 252 LMC. Para optar a los Títulos, Licencias y Certificados de la Marina Mercante, se requiere haber aprobado los cursos correspondientes y cumplir con los requisitos establecidos en la ley y los reglamentos.

${ }^{25}$ Gaceta Oficial de la República Bolivariana de Venezuela, N. 5.752 Extraordinario de 03 de enero de 2005.

${ }^{26}$ Como el Reglamento Parcial de la Ley de Títulos, Licencias y Permisos de la Marina Mercante sobre el Cómputo del tiempo de navegación de los pilotos oficiales para la Obtención de Títulos, Licencias y Permisos de la Marina Mercante (Gaceta Oficial de la República Bolivariana de Venezuela N. 283.607 de 12.02.1993).

${ }^{27}$ Este también es el sentido del Artículo 4 del Reglamento de la Ley del Trabajo sobre el Trabajo en la Navegación Marítima Fluvial y Lacustre: «Para la suscripción de un Contrato de Enganche, el tripulante debe estar inscrito ante la autoridad marítima respectiva».

${ }^{28}$ Artículo 22 LMAC. El Capitán de Puerto comprobará y certificará que la tripulación del buque cumpla con las normas legales que rigen la materia y que cada uno de los oficiales y restantes miembros de la 
tener, a los ojos de la LOTTT, como tal, entendiendo por este el «jefe superior de la nave, encargado de su gobierno y dirección, investido de autoridad pública y representante del propietario, del armador del buque y de los cargadores en todo lo relativo al interés del buque, su carga y al resultado de la expedición marítima» ${ }^{29}$.

El reconocimiento del cargo desde el punto de vista del derecho laboral no se traslada a las autoridades acuáticas. Si accede de facto al gobierno de la nave no debe mantenerlo hacia el futuro, lo contrario implicaría poner en riesgo la seguridad de la navegación y hacer nugatorias las competencias de las autoridades acuáticas. La importancia teleológica de la estabilidad individual no es mayor que el riesgo que supone para bienes y personas que una persona inepta gobierne la nave, por ello sabiamente el legislador de 1955 dispuso en el art. 672 del Código de Comercio (CCom) que la «inhabilitación para desempeñar las funciones y cumplir los deberes de sus respectivos cargos» era causa de despido pero ni la posterior LOT ni la LOTTT recogieron esta causa de modo expreso como sí lo hicieron con otras causas mencionadas por el artículo ${ }^{30}$, si los motivos de despido en la legislación laboral son numerus clausus o apertus o que el art. 652 CCom es aplicable es algo que escapa al alcance de este trabajo, de aplicarse no habría inconveniente para finalizar la relación de trabajo, pero si las causas de terminación de la relación laboral solo fueran las señaladas en la LOTTT - obviemos solo para fines teóricos la potencial carencia de inamovilidad y estabilidad - y las autoridades acuáticas impidiesen el embarque o el desempeño de ese «capitán» o cualquier otra persona para un cargo que requiera titulación o habilitación administrativa ¿cuáles serían los efectos sobre la relación de trabajo? Es obligación personalísima de la gente de mar obtener y mantener al día todo aquello que las autoridades acuáticas le requieran para embarcar y desempeñar determinada función en la nave, cuando no lo tiene está imposibilitado legalmente para la continuidad de la labor y cumplir su obligación principal: gobernar sobre la nave. Si el impedimento es insubsanable nos encontramos ante un imposibilidad legal de ejecutar el trabajo y por lo tanto ante un incumplimiento ${ }^{31}$ definitivo que

tripulación posee su título, licencia, permiso, refrendo o certificado de competencia debidamente actualizados, así como su cédula marina expedida de conformidad con las disposiciones reglamentarias.

Artículo 40 LMAC. El Capitán de Puerto no autorizará zarpe a ningún buque nacional o extranjero, que a su juicio, se encuentre mal estibado o que presente peligro para la seguridad, o que, en general, se encuentre en situación de incumplimiento de disposiciones establecidas en la ley.

${ }^{29}$ MARTÍNEZ, Patricia, "Los Sujetos de la Navegación en la nueva Ley de Comercio Marítimo" III Congreso de Derecho Marítimo, Asociación Venezolana de Derecho Marítimo. Caracas, 2004, p 219

${ }^{30}$ Embriaguez e insubordinación.

${ }^{31} \mathrm{Si}$ el vicio existía al momento de la «formación» del contrato, según cierta corriente, no puede hablarse de incumplimiento, sino de un responsabilidad precontractual, o culpa in contrahendo, que por un lado convierte al contrato en inejecutable, nulo o anulable y no hay propiamente obligaciones que cumplir o incumplir. La víctima, sino son los dos autores del gazapo, estaría en el derecho de exigir la compensación de los daños que pudiera sufrir fundada en la responsabilidad delictual, no la contractual. Si a pesar de la nulidad alguna parte ejecutó alguna de sus obligaciones tendría derecho a que la otra parte ejecute la contraprestación correspondiente pues lo contrario sería admitir el enriquecimiento injusto de uno. Cuando se considera la responsabilidad la correlación entre el daño y la reparación debe ser exacto, no mayor no menor. 
facultaría la terminación del contrato de trabajo ${ }^{32}$, o la reubicación en otro cargo si las partes a ello accedieran ${ }^{33}$. Además siendo el contrato de trabajo un contrato bilateral ante la falta de prestación del servicio no surge en cabeza del patrono ninguna obligación cuya contrapartida o causa sea tal servicio.

Hay tendencia a prescindir de las herramientas del derecho común para resolver casos del trabajo, el art. 16 LOTTT hace un buen esfuerzo en ello, pero es vano pues la LOTTT no es cuerpo normativo aislado y no relacional, existe y se integra dentro de un orden jurídico dado, fuera de él no existe. La realidad es que la LOTTT tiene una regulación pobre sobre las especificidades del trabajo de la gente de mar, al igual que resulta insuficiente para analizar las consecuencias que surgen de la inhabilidad del trabajador al momento de la contratación ${ }^{34}$ o cuando ésta es posterior ${ }^{35}$, o los efectos del conocimiento del vicio por parte del patrono ${ }^{36}$.

La ilicitud de la obligación del trabajador, originaria o sobrevenida, como, salvando las distancias, lo es la labor de transporte de drogas ilegales, vicia al contrato pues le falta un elemento esencial para su validez: objeto lícito (arts. 1.141 y $1.155 \mathrm{CC}$ ), el objeto de los contratos es crear obligaciones y —a efectos de este trabajo, sin ánimos de entrar al ruedo a debatir entre causalistas y anticausalistas - la causa de la obligación del patrono es la ejecución de la obligación de quien contrató como capitán sin serlo o no poder ejercerlo. En este escenario el contrato no tendría un objeto lícito, y al menos una obligación principal no tendría causa lícita, y podría ser, según que corriente se siga, nulo, inejecutable o caduco, o en el mejor de los casos afectado por un vicio convalidable si el capitán pudiera obtener la habilitación administrativa. La solución es la extinción del contrato $^{37}$, se apele al mecanismo que se desee, se puede entender que la imposibilidad

\footnotetext{
${ }^{32}$ Sería un incumplimiento grave de las obligaciones que impone la relación de trabajo y, probablemente también, dolo, negligencia o imprudencia que afecta la seguridad en el trabajo (art. 79 LOTTT). Esto cuando se analiza desde el incumplimiento unilateral del trabajador.

${ }^{33}$ El patrono no está obligado a reubicarle, no existe tal obligación en la LOTTT, si lo contrató como capitán es porque le requería para eso, o no hay otro cargo apropiado para él en la organización. Pero no podemos obviar que por vía de aplicación supletoria de la LOPCYMAT podría tratar de forzarse artificialmente a que el patrono le reubicare como si de una persona de capacidad disminuida se tratare, este enfoque no es ni sería correcto pues la LOPCYMAT pretende proteger a la persona con una disminución física o psíquica, no a quien culpablemente ha omitido titularse, el motivo de protección excepcional no existe aquí.

${ }^{34}$ El vicio surge en la conformación y acarrearía responsabilidades sobre los daños, de haberlos. Se discute si se trataría de responsabilidad contractual o delictual, hay quienes abogan por sistemas intermedios otros por sistemas de responsabilidad unificados, en fin, para efectos de este artículo asumiremos que siendo ilícito el objeto del contrato la única manera de restituir el orden jurídico vulnerado es teniendo el contrato por ineficaz, y aún cuando pueda tener vigencia temporal mientras su nulidad se declare o se detecte, una vez declarada esta los efectos jurídicos del contrato quedan aniquilados lo que deja un barniz de incongruencia el tratar de usar el contrato inexistente en derecho para determinar las responsabilidades y obligaciones de los fallidos contratantes.

${ }^{35}$ En este caso la ilicitud afecta la modificación del contrato, no el contrato de trabajo como un todo, por lo tanto el empleado impedido de gobernar la nave debería regresar a su puesto previo sin afectar las estipulaciones contractuales no relacionadas con el ascenso.

${ }^{36}$ Si no le era conocido será una víctima, de haber daño, por ejemplo los gastos incurridos al armar la nave para un viaje que nunca se emprendió por la incapacidad del capitán y tendría acción para resarcirse bien por responsabilidad delictual, si el vicio se produjo al momento de la formación, o bien contractual si la inhabilidad ocurrió luego de la formación del contrato

${ }^{37} \mathrm{Y}$ en el mejor e los caso su mutación.
} 
impuesta por las autoridades acuáticas sea una causa ajena a la voluntad de las partes (art. 76 LOTTT), o en caso de que el trabajador silenciara su inhabilidad proceder al despido por falta de probidad (art. 77 LOTTT). Si el impedimento fuera subsanable el contrato no podría ejecutarse mientras subsista, no podría ser una causa de suspensión de la relación de trabajo porque no es ninguno de los supuestos previstos por el art. 72 LOTTT a menos que las partes acuerden suspenderlo y, salvo que el contrato pactara otra cosa, el servicio se presume continuado y al no poder serlo el contrato no puede ejecutarse del modo pactado y existe un incumplimiento esencial que puede dar lugar a su terminación, quizá pueda haber salvedades si es subsanable en un corto período de tiempo, y ello no ocasiona daño sensible al armador o empleador, por ejemplo si puede resolver el entuerto mucho antes del inicio de la aventura marítima, y así preservar la continuidad del vínculo como lo tiende a favorecer la LOTTT esto último solo sería aplicable para enervar la extinción del contrato por incumplimiento de la obligación del trabajador no para enervar acción por falta de probidad si fuera el caso.

Otras interrogantes recaen sobre los efectos internos del ejercicio efectivo del gobierno de la nave en ilegal desempeño. La posición de la jurisprudencia, y no conocemos objeciones en la doctrina, es que no priva al trabajador de los beneficios de índole laboral derivados de su trabajo como capitán silenciando el elemento ilícito del desempeño. Este tampoco es el objeto de este breve trabajo, pero no podemos dejar pasar la oportunidad para hacer unas brevísimas consideraciones. Cuando el patrono ha tomado provecho del servicio, siendo el contrato de trabajo de ejecución sucesiva al igual que un arrendamiento de bienes - tiempo atrás al contrato de trabajo se le llamaba arrendamiento de servicios, las prestaciones ya ejecutadas no pueden retrotraerse, es de suyo imposible deshacer un prestación de servicios o el goce de lo arrendado ya consumados. La terminación del contrato por cualquier vía causará la desvinculación hacia el futuro. El derecho debe ser cierto, inexorable y armónico, si fue vulnerado ese hecho no puede cambiarse, lo único que puede hacerse es deducir los efectos del ilícito e impedir que continúe la violación. La doctrina moderna ha tendido a mitigar la posición clásica de las nulidades que está resumida en la máxima quod nullum est nullum producit effectum, que no ha pasado nunca de ser una ficción, y entiende, aunque no unánimemente, que la nulidad no puede borrar de la realidad lo ya hecho, solo aniquila los efectos que atenten contra la norma permaneciendo aquellos cuyo exterminio no es necesario o posible y así es imposible para el juez devolver tanto al trabajador el servicio ejecutado como al propietario el tiempo que el inquilino disfrutó, por lo que en justicia procede conceder la compensación justa por los cumplimientos aprovechados por la otra parte. Como cumplimiento y terminación operan en momentos distintos, nunca se yuxtaponen, resulta asombroso encontrar sentencias, y ciertos autores de cuyo nombre es preferible olvidarse, que sostienen que no es posible acumular pretensiones de resolución y cumplimiento del pago de las obligaciones derivadas del tiempo de uso del bien o del servicio por contradictorias aunque luego de fatigar su entendimiento conceden que tal pago puede pretenderse como daño derivado del incumplimiento. Estos dislates no han permeado la jurisprudencia laboral, ni deben hacerlo. Ejecutada por el empleado su obligación principal derivada del contrato de trabajo, aún cuando éste se aniquile, nacería en cabeza del patrono la 
obligación de pagar las contraprestaciones que de ello pudieran derivar, efecto típico del contrato sinalagmático, permitiendo al trabajador obtener económico provecho de su ilícito, e incluso tener acción ante tribunal del trabajo cuando en principio «ningún tribunal prestará su ayuda a un hombre que funda su causa de acción en un acto inmoral o ilegal» ${ }^{38}$, pues en defensa de su integridad el orden jurídico no concede, como medio de autoprotección, acción con tal fundamento. En ciertos sistemas la pérdida queda en el lugar en el cual cayó, en Venezuela si el patrono ha aprovechado el ilícito debe compensar al trabajador por que el título no sería solo la ejecución del acto, sino el aprovechamiento del acto para un acto lícito: el transporte acuático. Si se evitara que el trabajador obtuviera la compensación por su trabajo basados solo en la ilicitud de su cargo el patrono obtendría un doble beneficio de la ejecución del trabajo: el aprovechamiento del servicio prestado y la retención del pago por ese servicio, mientras que el trabajador no solo no obtendría beneficio alguno sino que sufriría la pérdida de su tiempo y esfuerzo no recuperables, probablemente sea culpable del ilícito, pero ese dato por sí solo no puede ser causa del enriquecimiento injusto del patrono. El Código Civil venezolano no tiene regulaciones específicas sobre el punto, y aún cuando las tuviera las reticencias de la jurisdicción laboral a aplicar normas civilistas y contractualistas ${ }^{39}$ las harían poco menos que una fuente lejana, por no decir inexistente, para la solución del conflicto, en todo caso es interesante que establezca que las obligaciones con causa ilícita son ineficaces ${ }^{40}$ y aún más interesante es lo previsto por el Código Civil español ${ }^{41}$ donde diferencia los efectos de la nulidad de una obligación cuyo objeto es ilícito si tal ilicitud es derivada de un hecho que sea o no falta o delito ${ }^{42}$, pero si la legislación civil venezolana poco permea las

\footnotetext{
${ }^{38}$ Holman v Jhonson (1775) 1 Cowp 34. Lord Mansfield sostuvo esta famosa máxima, hoy se entiende que no es un principio inflexible, aunque sigue siendo un común punto de partida en el análisis de las acciones derivadas de los ilícitos. Claro que donde haya múltiples autorías, eventos o eslabones de la cadena causal habría que analizar cada pieza, pero cuando el único título de pedir deriva solo de un ilícito la acción ${ }^{39} \mathrm{La}$ inserción de la relación de trabajo como figura sustitutiva del contrato de trabajo en la LOTTT ha infectado el pensamiento de la doctrina y la jurisprudencia que, salvo en contados y honorables casos, pasa de largo de las herramientas desarrolladas a lo largo de los siglos para la solución de las vicisitudes de la vida de los contratos civiles.

${ }^{40}$ Artículo $1.157^{\circ}$

La obligación sin causa, o fundada en una causa falsa o ilícita, no tiene ningún efecto.

La causa es ilícita cuando es contraria a la Ley, a las buenas costumbres o al orden público.

Quien haya pagado una obligación contraria a las buenas costumbres, no puede ejercer la acción en repetición sino cuando de su parte no haya habido violación de aquéllas.

${ }^{41}$ Real Decreto de 24 de julio de 1889 por el que se publica el Código Civil, publicado originalmente en «Gaceta de Madrid» núm. 206, de 25/07/1889. (BOE-A-1889-4763).

${ }^{42}$ Artículo 1305.

Cuando la nulidad provenga de ser ilícita la causa u objeto del contrato, si el hecho constituye un delito o falta común a ambos contratantes, carecerán de toda acción entre sí, y se procederá contra ellos, dándose, además, a las cosas o precio que hubiesen sido materia del contrato, la aplicación prevenida en el Código Penal respecto a los efectos o instrumentos del delito o falta.

Esta disposición es aplicable al caso en que sólo hubiere delito o falta de parte de uno de los contratantes; pero el no culpado podrá reclamar lo que hubiese dado, y no estará obligado a cumplir lo que hubiera prometido.

Artículo 1306.

Si el hecho en que consiste la causa torpe no constituyere delito ni falta, se observarán las reglas siguientes: 1.a Cuando la culpa esté de parte de ambos contratantes, ninguno de ellos podrá repetir lo que hubiera dado a virtud del contrato, ni reclamar el cumplimiento de lo que el otro hubiese ofrecido.
} 
decisiones de los jueces laborales poco habrá que esperar de la influencia civil española. En todo caso si se obvia el tema de la ilicitud por la jurisprudencia y doctrina laboral se puede generar un escenario inaudito: un contrato inejecutable para las autoridades acuáticas pero vigente para las autoridades laborales, al patrono le resultaría un contrato inútil y la vulneración del orden jurídico se mantendría en pie.

Dejando a un lado el tema de la ilicitud, el capitán es quien dirige y gobierna el buque, preserva el orden y es responsable salvar personas y carga en caso de peligro. Es su máxima autoridad a quien se sujetan todos los que a bordo están ${ }^{43}$. Dentro de esta gobernanza, se entiende que imparte las órdenes y representa al patrono ${ }^{44}$ al punto que su desobediencia es causal de despido justificado para el art. 261 LOTTT $^{45}$. Este poder de representación no es voluntario y deriva automáticamente del mandato legal de la LOTTT, que no es novedoso sino que recoge ya regulaciones similares de leyes del trabajo anteriores y permite a quien es reputado como representante del patrono a que haga sus veces ante los trabajadores con formidables facultades de disposición, a título de ejemplo se les permite negociar y suscribir convenciones colectivas, a veces en extremo onerosas, sin esperar ni requerir poder especial ni opinión expresa del propio patrono, y pueden actuar en su representación en sede administrativa laboral, pero ese poder de representación no ha llegado a las actuaciones judiciales donde no pueden apersonarse en juicio porque en Venezuela, por regulaciones propias de la legislación relativa al ejercicio de la profesión de abogado solo quien es abogado puede ejercer poderes de representación en juicio ${ }^{46}$ y no es raro encontrar sentencias donde este efecto

2.a Cuando esté de parte de un solo contratante, no podrá éste repetir lo que hubiese dado a virtud del contrato, ni pedir el cumplimiento de lo que se le hubiera ofrecido. El otro, que fuera extraño a la causa torpe, podrá reclamar lo que hubiera dado, sin obligación de cumplir lo que hubiera ofrecido.

${ }^{43}$ Art. 51 LMAC.

${ }^{44}$ Art. 41 LOTTT. Los ... capitanes o capitanas de buques o aeronaves, (...) y demás personas que ejerzan funciones de dirección o administración se considerarán representantes del patrono o de la patrona aunque no tengan poder de representación, y obligarán a su representado o representada para todos los fines derivados de la relación de trabajo.

${ }^{45}$ En igual sentido el derogado artículo 352 LOT:

En el trabajo en la navegación marítima, fluvial y lacustre, son causas justificadas de despido, además de las previstas en el artículo 102 de esta Ley, los siguientes hechos del trabajador: a) ... c) El uso a bordo de drogas sin prescripción médica que acredite que su ingestión no altera su capacidad de servicio. Cuando fuere el caso, al subir el trabajador a bordo deberá informar al Capitán y presentarle la prescripción suscrita por el médico;

d) La insubordinación y desobediencia a órdenes del Capitán, en su carácter de autoridad;

Artículo 261. Causales de despido justificado

En el trabajo en la navegación marítima, fluvial y lacustre, son causas justificadas de despido, además de las previstas en la presente Ley, los siguientes hechos del trabajador o de la trabajadora:

a) La falta de asistencia a bordo a la hora convenida para la salida o que presentándose, desembarque y no haga el viaje;

b) La embriaguez a bordo.

c) El uso a bordo de drogas sin prescripción médica que acredite que su ingestión no altera su capacidad de servicio. Cuando fuere el caso, al subir el trabajador o la trabajadora a bordo deberá informar al capitán o la capitana y presentarle la prescripción suscrita por el médico o la médica.

d) La insubordinación y desobediencia a órdenes del capitán o la capitana, en su carácter de autoridad.

${ }^{46}$ La Ley de Abogados, textualmente establece que:

"Articulo 3. Para comparecer por otro juicio, evacuar consultas jurídicas, verbales o escritas y realizar cualquier gestión inherente a la abogacía, se requiere poseer el título de abogado, salvo las excepciones contempladas en la Ley. 
se extiende al punto, discutible, de no permitir a quien no es abogado sustituir sus propios poderes de representación pues se entiende que la facultad de actuar en juicio en representación de otro sin ser abogado es nula ab initio y al no poder ser considerada existente en derecho no puede transmitirse a otros aún siendo los recipientes de la sustitución abogados. En todo caso ese poder de representación que surge del art. 41 LOTTT se circunscribe al ámbito laboral, facultades son también en cierta forma recogidas en el artículo $671 \mathrm{CCom}^{47}$. El capitán debe responder por los actos de la tripulación conforme al art. $630 \mathrm{CCom}^{48}$ y cuando se halle en alta mar o en aguas territoriales de otro estado es delegado de la Autoridad Política ${ }^{49}$. En España, por hacer una rápida referencia, el art. 171 de la Ley 14/2014, de 24 de julio, de Navegación Marítima (BOE de 25 julio 2014) le hace jefe de la dotación, le da el gobierno de la nave y también le otorga la categoría de representante mismo de la autoridad pública.

Las normas citadas de la legislación venezolana parecen no dejar duda de que el capitán es persona que ejerce «funciones de dirección y administración» sobre la nave, así como sobre los bienes y personas en ella situados, y que representa al patrono obligándole «para todos los fines de la relación de trabajo» respondiendo personalmente por sus subordinados. Por ello es normal que las sentencias citadas solo se centren en analizar la realidad de los hechos en el caso que se les presenta, pues ante la claridad de la redacción, si el trabajador en efecto ejerce las formidables facultades que la legislación venezolana le confiere, poco puede dudarse de su capacidad de tomar decisiones relevantes sobre el buque, el viaje, las mercancías, las personas; así como de su capacidad de obligar al patrono con sus actos, sustituirlo y representarlo. Pero la claridad legislativa no siempre se refleja en la práctica, una cosa es tener las facultades y otra ejercerlas. La tendencia actual es que las funciones del capitán se han erosionado por una conjunción de factores: progresos técnicos en transporte y comunicaciones, rotación acelerada, estadías portuarias reducidas, aumento de los colaboradores comerciales, la especialización en la gestión de diversos aspectos del negocio marítimo, el resultado de esto es que la figura del capitán se ha ido eclipsando en la gestión comercial y de la tripulación, no así su mando técnico y funciones públicas ${ }^{50}$, sobre esto último volveremos adelante.

Los representantes legales de personas o de derechos ajenos, los presidentes o representantes de sociedades cooperativas, asociaciones o sociedades civiles o mercantiles que no fueren abogados, no podrán comparecer en juicio a nombre de sus representantes sin la asistencia de abogados en ejercicio.

Articulo 4. Toda persona puede utilizar los órganos de la administración de justicia para la defensa de sus derechos e intereses. Sin embargo, quien sin ser abogado deba estar en juicio como actor, como demandado o cuando se trate de quien ejerza la representación por disposición de la Ley o en virtud de contrato, deberá nombrar abogado, para que lo represente o asista en todo el proceso."

47 Cuando el capitán despide a oficiales o a marineros con causa legítima debe pagarles sus salarios convenidos hasta el día de la despedida, calculados según el camino hecho.

Si la despedida tuviere lugar antes de principiar el viaje, serán pagados por los días que hubieren servido.

${ }^{48}$ Artículo 630. El capitán es civilmente responsable por culpa, impericia o negligencia en el cumplimiento de sus deberes; sin perjuicio del procedimiento criminal a que se haga acreedor por fraude o dolo.

Es también responsable por los hurtos cometidos por la tripulación, salvo sus derechos contra los culpados; y de los daños causados por las riñas de la gente de mar, y por sus faltas en el servicio de la nave, a menos que justifique que puso en ejercicio su autoridad para precaverlas, impedirlas o corregirlas oportunamente. ${ }^{49}$ Art. 51 LMAC.

${ }^{50}$ DÍAZ DE LA ROSA, Angélica, “ Los Contratos de Gestión de Tripulación de Buques: Crew Management Agreements" La Ley, Madrid, 2011, p. 33 
En España, aun cuando la definición que su legislación laboral hace del personal de alta dirección ${ }^{51}$ no coincide con exactitud con nuestro trabajador de dirección, se discute sobre la naturaleza del cargo de capitán y si éste puede o no calificarse como de alta dirección, este debate, harto interesante, desenvuelve en el tiempo los cambios que las innovaciones han impuesto al capitán y como han modificado poco a poco su impronta en la nave forzando a nuevos análisis jurídicos. El Tribunal Supremo - España - en sentencia STS $3485 / 1990$ de 30.04.1990 52 dijo que la relación del capitán «se inserta plenamente en el ámbito de la relación especial del personal de alta dirección». En fecha más reciente el Tribunal Superior de Justicia de Galicia en sentencia STSJ GAL 3961/2017 de 30.05.2017 discurrió en términos semejantes ${ }^{53}$ calificando al capitán como empleado de alta dirección. Pero, estas tesis no son uniformemente aceptadas. Hay voces discordantes:

${ }^{51}$ El Real Decreto 1382/1985, en su art. 1.2, lo define así: «...aquellos trabajadores que ejercitan poderes
inherentes a la titularidad jurídica de la Empresa, y relativo a los objetivos generales de la misma, con
autonomía y plena responsabilidad sólo limitadas por los criterios e instrucciones directas emanadas de la
persona o de los órganos superiores de gobierno y administración de la Entidad que respectivamente ocupe
aquella titularidad.»
${ }^{52}$ «En efecto, como ya expresa la sentencia de esta Sala de 3 de marzo de 1990 , «el texto no exige que
únicamente merezca tal calificación el alter ego de la Empresa, el titular del puesto-vértice de su estructura
piramidal, sino que también comprende a los que, dotados de los correspondientes poderes, asuman altas
funciones directivas en sectores específicos del tráfico empresarial», y no es dudoso que tales funciones
(expresivas de una efectiva atribución de poder empresarial de decisión, así sentencias de 15 de julio y 12
de septiembre de 1986) son las que ejerce el Capitán de la Marina Mercante en el buque, considerado como
autónomo centro de trabajo ( art. 1.5 del Estatuto de los Trabajadores ), con las amplísimas facultades de
dirección y representación que le confieren los arts. 610 y siguientes del Código de Comercio, así como
las que, en el marco del mando y gobierno del buque le atribuyen los arts. 15 y concordantes de la Ordenanza
ya mencionada . Es oportuno añadir, a todo ello, la referencia que el propio art. 90 de la Ordenanza hace a
«la naturaleza especial y múltiple de la representación que ostentan y funciones encomendadas a los
Capitanes...", el marco de confianza en que se produce la relación entre Capitán y Naviero, y la evidencia
de que el resultado de la gestión de aquél mando del buque es factor decisivo para el éxito o fracaso de la
Empresa.» 53 “.... debe recordarse que la doctrina jurisprudencial, desde las SSTS de 3 marzo 1990 (RJ 1990\1752 ), 26 marzo 1990 (RJ\199012342 ) y 30 abril 1990 (RJ 199013513), ha sentado el criterio de que "la naturaleza de la relación laboral existente entre los cargos de confianza del buque, entre ellos, el capitán de un buque (en este caso de salvamento) y su empleadora, aboca a la conclusión de que ésta se inserta plenamente en el ámbito de la relación especial del personal de alta dirección, regulada por el Real Decreto 1382/1985, visto que, según su artículo 1.2 , se entiende como incluidos en este personal a «aquellos trabajadores que ejercitan poderes inherentes a la titularidad Jurídica de la Empresa, y relativo a los objetivos generales de la misma, con autonomía y plena responsabilidad sólo limitadas por los criterios e instrucciones directas emanadas de la persona o de los órganos superiores de gobierno y administración de la Entidad que respectivamente ocupe aquella titularidad». En efecto, como ya expresa la Sentencia del TS de 3 de marzo de 1990 (RJ 1990\1752), «el texto no exige que únicamente merezca tal calificación el alter ego de la empresa, el titular del puesto-vértice» de su estructura piramidal, sino que también comprende a los que, dotados de los correspondientes poderes asuman altas funciones directivas en sectores específicos del tráfico empresarial», y no es dudoso que tales funciones -expresivas de una efectiva atribución del poder empresarial de decisión, así Sentencias de 15 de julio y 12 de septiembre de 1986 (RJ 198614139 y RJ 1986 14958)-, son las que ejerce el Capitán de la Marina Mercante en el buque, considerado como autónomo centro de trabajo ( art. 1.5 del Estatuto de los Trabajadores ), con las amplísimas facultades de dirección y representación que le confieren los artículos 610 y siguientes del Código de Comercio así como las que, en el marco del mando y gobierno del buque le atribuyen los artículos 15 y concordantes de la Ordenanza ya mencionada. Es oportuno añadir, a todo ello, la referencia que el propio artículo 90 de la Ordenanza hace a «la naturaleza especial y múltiple de la representación que ostentan y funciones encomendadas a los Capitanes...» el marco de confianza en que se produce la relación entre Capitán y Naviero, y la evidencia de que el resultado de la gestión de aquél al mando del buque es factor decisivo para el éxito o fracaso de la empresa". Y un criterio semejante ha sostenido también la STC 103/1990, de 4 de junio, al asimilar a un 
Hay quien llega a considerar que, partiendo de la definición de personal de alta dirección planteada por el art. 1.2 del RD 1382/1985, el capitán no es una persona que pueda ejercitar «poderes inherentes a la titularidad jurídica de la empresa» con «autonomía y plena responsabilidad» de forma ordinaria, ya que, quedan restringidos a los casos extraordinarios de necesidad urgente y ausencia del naviero o representante suyo. Circunstancias que, por otra parte, raramente se alcanzarán en la actividad marítima actual. ${ }^{54}$ Pero el art. $185^{55}$ de la Ley 14/2014, de 24 de julio, de Navegación Marítima omite toda referencia a circunstancias extraordinarias para representar al armador, en el giro ordinario del devenir de buque obliga y representa a su principal por causa de ley de allí que la objeción derivada de la extraordinariedad puede haber quedado obsoleta.

No se requiere en Venezuela que el trabajador de dirección ejerza poderes inherentes a la titularidad de la empresa, por lo que la discusión de su carácter de dirección no necesariamente debe seguir los mismos derroteros, pero, sin dudas, la evolución siempre obligará a revisar las normas que regulan la figura, su interpretación, y, por sobre todo, el caso concreto y cuáles de las facultades del capitán han desaparecido o restringido, o cuáles nuevas aparecen o aumentan, para, en una constante evolutiva del derecho, del comercio y del trabajo, se ajusten en el tiempo las regulaciones, o la visión e implementación de ellas. Otra diferencia relevante entre España y Venezuela es que los cambios de legislación ocurridos en el siglo XXI han quitado relevancia a la figura del empleado de confianza, durante buena parte del siglo pasado la figura del trabajador o empleado de confianza tenía un trato diferenciado y podía ser despedido libremente, pero ya no, por ello toda consideración del capitán como empleado de confianza es, en este momento, irrelevante para el derecho venezolano porque esa cualidad no causa efecto jurídico alguno.

Por ahora mencionemos que desde el punto de vista laboral la LOTTT en sus arts. 246, 251, 252, 256 y 259 reafirma el carácter de representante del patrono del capitán tanto

puesto de mando del buque (en este caso un Jefe de máquinas de un buque arrastrero al fresco), a los altos directivos, dando lugar el cese unilateral del empleador a la indemnización por desistimiento prevista en el art. 11. 1 del RD 1382/1985. Por su parte, la STSJ de Asturias de 14 de febrero de 2017 (rec. 2732/2016; ROJ: STSJ AS 404/2017 - ECLI:ES:TSJAS:2017:404), que contempla el supuesto semejante de cese en el puesto de capitán de otro trabajador de la misma empresa y su traslado a un buque distinto como primer oficial, declara dicho cese -después de asimilarlo a un alto directivo-, como constitutivo de despido improcedente por entender que, a la vista de la ambigüedad de la carta, la empresa no desistió del contrato, sino que despidió al trabajador por motivos disciplinarios, aplicando entonces la indemnización de 20 días de salario por año de servicio ( art. 11. 2 del RD 1382/1985 ), en vez de los siete días por año de servicio previstos para el supuesto de desistimiento del empresario ( art. 11.1 del aludido RD 1382/1985 )"

${ }^{54}$ ALEMANY YERN, Marcos. La responsabilidad del capitán del buque tras la implantación del código ISM. Trabajo final de carrera, presentado ante la Facultad Politécnica de Cataluña. 2005. Consultado en https://upcommons.upc.edu/bitstream/handle/2099.1/6358/Cap\%C3\%ADtulo\%202.pdf?sequence=5\&isA llowed=y

55 1. El capitán ostenta la representación del armador para contraer por cuenta de éste cuantas obligaciones se refieran a las necesidades ordinarias del buque.

2. El armador quedará obligado al cumplimiento de tales obligaciones sin que quepa alegar abuso de confianza o transgresión de las facultades conferidas.

3. Queda a salvo la responsabilidad que incumba al capitán frente al armador por los actos y contratos realizados contraviniendo las legítimas y expresas instrucciones impartidas por éste.

4. El capitán estará activa y pasivamente legitimado para comparecer como representante del armador en todos los procedimientos judiciales o administrativos concernientes al buque de su mando. 
frente a los trabajadores como a las autoridades, venezolanas o extranjeras. Por ejemplo, debe notificar al capitán del buque:

(1) El tripulante que quiere rescindir su contrato de trabajo antes de la salida del buque ${ }^{56}$.

(2) El Capitán de Puerto, de la orden girada a la tripulación para permanecer a bordo por mal tiempo ${ }^{57}$.

Pero también la legislación acuática le da ese carácter de representante no solo de quien se considere patrono, sino del armador del buque, del cargador y del propietario de la nave en «en todo lo relativo al interés del buque, su carga y al resultado de la expedición marítima», estás son las textuales palabras del artículo 18 de la Ley de Comercio Marítimo. Este mismo cuerpo legislativo ${ }^{58}$ le permite vender y gravar las mercancías que transporta, y adquirir obligaciones a cuenta del armador. Por lo tanto posee facultades para disponer, enajenar, gravar las mercancías y asumir obligaciones en nombre del armador. También posee atribuidas legislativamente la responsabilidad y facultad para dirigir al personal del buque, tales como:

(1) Establecer, y participar, el servicio de guardia de puerto, seleccionando el personal para ello el cual no podrá abandonar el buque ${ }^{59}$.

(2) Ordenar labores de reparación o de recorrida para resguardo de la seguridad del buque ${ }^{60}$.

\footnotetext{
${ }^{56}$ Artículo 246. Los contratos de trabajo que deban vencerse en los ocho días anteriores a la conclusión de un viaje cuya duración exceda de este término, podrán ser rescindidos por los y las tripulantes que tengan interés, sin pago de indemnización, dando aviso al capitán o a la capitana con setenta y dos horas de anticipación a la salida del buque.

${ }^{57}$ Artículo 256. Cuando el capitán o la capitana de Puerto o la persona que haga sus veces, en previsión de mal tiempo, dispusiere que la tripulación de un buque debe estar completa a bordo, el capitán o la capitana del buque lo hará saber a los y las tripulantes por medio de un aviso al alcance de todos, todas y anotará esa circunstancia en el diario de navegación.

Artículo 347. Cuando el Capitán de Puerto o la persona que haga sus veces, en previsión de mal tiempo, dispusiere que la tripulación de un buque debe estar completa a bordo, el Capitán del buque lo hará saber a los tripulantes por medio de un aviso al alcance de todos y anotará esa circunstancia en el Diario de Navegación.

${ }^{58}$ Artículo 24. Si el Capitán no obtiene los fondos requeridos, podrá contraer deudas para proveerse de ellos. A falta absoluta de otro recurso puede gravar o vender la carga, las provisiones o los equipos del buque.

Artículo 39. El armador responde civilmente de las obligaciones contraídas por el Capitán, en lo que concierne al buque y a la expedición marítima.

59 Artículo 251. Cuando el buque deba permanecer en puerto, dársena, rada, abrigada o dique, por más de veinticuatro horas y si el Capitán o la Capitana los considera necesario, se organizará el servicio de guardia de puerto. Organizado este servicio, se anotará esta circunstancia en el diario de navegación.

Establecido el servicio, se colocará diariamente una lista del personal de guardia, en lugar visible. El personal seleccionado a este fin no podrá abandonar el buque bajo ninguna circunstancia.

Artículo 342 Cuando el buque deba permanecer en puerto, dársena, rada, abrigada o dique, por más de veinticuatro (24) horas y si el Capitán lo considera necesario, se organizará el servicio de guardia de puerto. Organizado este servicio, se anotará esta circunstancia en el diario de navegación.

${ }^{60}$ Artículo 350. El trabajador deberá respetar y realizar las instrucciones y prácticas destinadas a prevenir riesgos en el mar, las que se efectuarán de conformidad con lo que determinen las leyes respectivas. Todo tripulante tiene la obligación de asistir a los zafarranchos de incendio, abandono del buque y otros ejercicios y maniobras de salvamento que ordene el Capitán sin que esto pueda ser considerado como trabajo extraordinario.
} 
(3) Ordenar zafarranchos y maniobras de salvamento; y estos trabajos nunca se consideraran horas extras ${ }^{61}$.

(4) Todo aquello que en caso de accidente deba hacerse ante las autoridades lo hará el capitán del buque ${ }^{62}$.

Las atribuciones del capitán no se circunscriben al ámbito acuático, mercantil y laboral; pues el legislador le otorga facultades propias de un funcionario público, entre otras tiene la potestad legal de producir documentos públicos, según la Ley de Comercio Marítimo ${ }^{63}$. Este ejercicio de ciertas funciones o poderes públicos no es una peculiaridad del sistema en Venezuela, puede observarse en otras latitudes, por ejemplo es una disposición común en el derecho interno de varios países de la Unión Europea, y esto ha generado un intenso

${ }^{61}$ Artículo 252. No serán consideradas como horas extraordinarias y en consecuencia, no darán derecho a
remuneración especial, las horas de trabajo invertidas en los siguientes casos, sin perjuicio de los demás
que contemplen las leyes pertinentes:
a) Cuando la seguridad del buque, de las personas embarcadas o del cargamento esté en peligro por neblina,
mal tiempo, incendio o naufragio, o por otras causas consideradas como de fuerza mayor;
b) Cuando a consecuencia de enfermedades, accidentes u otras causas semejantes de fuerza mayor,
sobrevenidas en el curso del viaje, el personal del buque se encuentre reducido. c) Cuando sea necesario instruir al personal en ejercicio de zafarranchos. d) Cuando por errores náuticos o negligencias, hubiere de efectuar trabajos extraordinarios, no tendrán derecho a remuneración los responsables directos de esos errores o negligencias. e) Cuando después de empezado un viaje sea necesario efectuar trabajo de recorrida o reparación en el aparejo del buque o en el departamento de máquinas, o cuando dichos trabajos sean ordenados por el Capitán o la Capitana por considerarlos indispensables para la seguridad del buque.

Artículo 343. No serán consideradas como horas extraordinarias y en consecuencia, no darán derecho a remuneración especial, las horas de trabajo invertidas en los siguientes casos, sin perjuicio de los demás que contemplen las leyes pertinentes:... e) Cuando después de empezado un viaje sea necesario efectuar trabajo de

recorrida o reparación en el aparejo del buque o en el departamento de máquinas, o cuando dichos trabajos sean ordenados por el Capitán por considerarlos indispensables para la seguridad del buque.

Artículo 259. El trabajador o la trabajadora deberá respetar y realizar las instrucciones y prácticas destinadas a prevenir riesgos en el mar, las que se efectuarán de conformidad con lo que determinen las leyes respectivas.

Todo tripulante tiene la obligación de asistir a los zafarranchos de incendio, abandono del buque y otros ejercicios y maniobras de salvamento que ordene el capitán o la capitana sin que esto pueda ser considerado como trabajo extraordinario.

${ }^{62}$ Artículo 260. Se regirán por las disposiciones de esta Ley y las demás que fueran aplicables especialmente en todo lo que no estuviera previsto en la Ley Orgánica de Prevención Condiciones y Medio Ambiente de Trabajo los accidentes de trabajo:

a) A bordo de buques nacionales.

b) A bordo de buques extranjeros, si el accidente ocurriese en aguas venezolanas.

c) En caso de accidentes ocurridos en trayecto, entendiéndose como tal el trayecto desde el lugar de residencia del trabajador o de la trabajadora al sitio de embarque y viceversa.

En estos casos el capitán o la capitana del buque cumplirá las formalidades establecidas en esta Ley ante la Capitanía de Puerto del lugar en que recale, una vez admitido el buque a libre plática.

Si el puerto de recalada es extranjero, esta formalidad se cumplirá ante el Cónsul de Venezuela si lo hubiere en el puerto, quedando obligado a hacerlo en todo caso al llegar a puerto venezolano.

Artículo 351. Se regirán por las disposiciones de esta Ley y las demás que fueren aplicables, los accidentes de trabajo: a) A bordo de buques nacionales; y b) abordo de buques extranjeros, si el accidente ocurre en aguas venezolanas. En estos casos el Capitán del buque cumplirá las formalidades indicadas en esta Ley ante la Capitanía de Puerto del lugar en que recale, una vez admitido el buque a libre plática.

Si el puerto de recalada es extranjero, esta formalidad se cumplirá ante el Cónsul de Venezuela, si lo hubiere en el puerto, quedando obligado a hacerlo en todo caso al llegar a puerto venezolano.

63 Artículo 21. Los asientos del diario de navegación que se refieren a la actuación del Capitán como delegado de la autoridad pública, tienen la fuerza de documento público. 
debate a raíz del art. 45 (antiguo art. 39) del Tratado de Funcionamiento de la Unión Europea $^{64}$. Este artículo garantiza la libre circulación de los trabajadores dentro de la Unión, pero exceptúa de ellos a quienes ejerzan la función pública. El problema surgió porque dadas las facultades que muchas legislaciones nacionales otorgan a sus capitanes se entendió que al poder ejercer funciones públicas no estaban amparados por la libre circulación. Hay dos casos emblemáticos resueltos por el Tribunal de Justicia de la Unión Europea en dos sentencias del 30.09.2003, el asunto C-405/01 sentencia ECLI:EU:C:2003:515 (caso Colegio de Oficiales de la Marina Mercante Española v Administración del Estado) y el asunto C-47/02 sentencia ECLI:EU:C:2003:516 (caso Albert Anker, Klaas Ras and Albertus Snoek v Bundesrepublik Deutschland). Los gobiernos español ${ }^{65}$, danés, alemán ${ }^{66}$, griego, francés e italiano sostenían que podían reservar a sus propios nacionales el empleo de capitán de un buque mercante bajo su pabellón pues, entre otros argumentos, los derechos nacionales daban al capitán prerrogativas para el mantenimiento de la seguridad, facultades de policía, atribuciones en materia notarial y de estado civil que no se deducían de modo directo y necesario de los requerimientos de mando del buque, sino de su condición de representante del poder público en provecho de los intereses generales del Estado de pabellón. Estas sentencias aceptan que puede tenerse por representante del poder público del estado del pabellón sin importar que sea empleado de una persona de derecho privado, pero terminan dando una interpretación restrictiva a la excepción del tratado en el sentido de que se «autoriza a un Estado miembro a reservar a sus nacionales los empleos de capitán y primer oficial de los

\footnotetext{
${ }^{64}$ 1. Quedará asegurada la libre circulación de los trabajadores dentro de la Unión.

2. La libre circulación supondrá la abolición de toda discriminación por razón de la nacionalidad entre los trabajadores de los Estados miembros, con respecto al empleo, la retribución y las demás condiciones de trabajo.

3. Sin perjuicio de las limitaciones justificadas por razones de orden público, seguridad y salud públicas, la libre circulación de los trabajadores implicará el derecho:

a) de responder a ofertas efectivas de trabajo;

b) de desplazarse libremente para este fin en el territorio de los Estados miembros;

c) de residir en uno de los Estados miembros con objeto de ejercer en él un empleo, de conformidad con las disposiciones legales, reglamentarias y administrativas aplicables al empleo de los trabajadores nacionales;

d) de permanecer en el territorio de un Estado miembro después de haber ejercido en él un empleo, en las condiciones previstas en los reglamentos establecidos por la Comisión.

4. Las disposiciones del presente artículo no serán aplicables a los empleos en la administración pública.

${ }^{65}$ En España diversas disposiciones atribuyen a los capitanes de buques mercantes funciones de seguridad, policía, fe pública y registro del estado civil; así, por ejemplo conforme al art. 300 del Real Decreto Legislativo 2/2011, de 5 de septiembre, por el que se aprueba el Texto Refundido de la Ley de Puertos del Estado y de la Marina Mercante (BOE núm. 253, de 20/10/2011) los capitanes pueden adoptar medidas de policía abordo.

66 En Alemania el Schiffsbesetzungsverordnung (Reglamento sobre la tripulación de los buques) de 26.08.1998 (BGB1. I, p. 323), modificado por el Reglamento de 29.10.2001 (BGB1. I, p. 2785) estableció en su artículo 2, apartado 2, que «Cualquiera que sea el arqueo bruto del buque, el capitán deberá ser alemán en el sentido de la Grundgesetz [Ley fundamental] y titular de un certificado de aptitud válido expedido en Alemania.»; la Seemannsgesetz (Ley sobre el marinero) de 26.07.1957 para el mantenimiento del orden y la seguridad a bordo le faculta para para utilizar la fuerza física o la detención provisional si las demás medidas parecen o han sido insuficientes, y el Ausführungsverordnung zum Personenstandsgesetz (Reglamento de desarrollo de la ley sobre el estado civil) de 12.08.1957, modificado por el Reglamento de 17.12.2001 (BGBl. I, p. 3752) le impone la facultad y el deber de levantar acta del nacimiento o de la muerte que le hayan sido notificados.
} 
buques mercantes que enarbolan su pabellón si las prerrogativas de poder público atribuidas a los capitanes y a los primeros oficiales se ejercen efectivamente de forma habitual y no representan una parte muy reducida de sus actividades», en fin, la primacía de la realidad determinará la intensidad del ejercicio de esa función pública para poder establecer las limitaciones de movilidad dentro del espacio europeo pero siempre que las tenga y las ejerza, sea cual sea su intensidad, será un representante público del estado de pabellón. El legislador venezolano, en el mismo tono de sus pares europeos, requiere que el capitán sea venezolano, lo prevé el artículo 27 LOTTT $^{67}$ que repite la regulación existente en la anterior LOT.

Para ir concluyendo, un cita relevante:

El Capitán, como institución mercantil, conserva su múltiple condición de delegado ad hoc de la autoridad pública, órgano auxiliar del registro civil, gerente de la nave y, en tal sentido, responsable por la seguridad de las personas, los bienes, el ambiente y factor del propietario o del armador, por una parte, representante de los cargadores en todo lo relativo al interés de la nave, su carga y el resultado... ${ }^{68}$

Cuando se ejercen este cúmulo de facultades propias del cargo de capitán, o una buena parte de ellas, haya o no titulación, la SCS tiende a calificarlo como trabajador de dirección como, por ejemplo, lo ha hecho en las sentencias de 23.11.2011 (caso Juvenal Antonio Medina vs. Transmarveca) ${ }^{69}$ y de fecha 10.11.2005 (caso Freddy Caldera), donde calificó al capitán como trabajador de dirección. Ciertamente si el trabajador desempeña las funciones y ejerce las facultades que las normas antes citadas le han conferido, es de suyo evidente que toma decisiones determinantes sobre el destino de la aventura acuática, muchas de su exclusiva responsabilidad, y que representa al patrono frente a los trabajadores, les ordena, contrata y despide, y sin necesidad de entrar a considerar las facultades accidentales que se le otorgan como funcionario público lo cual acrecienta su autoridad. Si el armador posee múltiples emprendimientos, múltiples buques, no por ello debe limitarse el carácter de trabajador de dirección del capitán pues, sostener, como algunos hacen, que al no decidir o participar en lo que se decide sobre la empresa como un todo sino sobre un trozo restringido de ella cuestiona y debilita su carácter de trabajador de dirección. Discurrir de este modo equivaldría a sostener que en una empresa multinacional solo quienes participan en la dirección del todo son trabajadores de dirección y por lo tanto quienes dirigen los destinos de una empresa en una zona, en un país determinado no son trabajadores de dirección, esto no puede ser el sentido de la

\footnotetext{
${ }^{67}$ Se requerirá la nacionalidad venezolana para ejercer ciertas responsabilidades, tales como: jefes de relaciones industriales, de personal, capitanes de buque, aeronaves, capataces o quienes ejerzan funciones análogas, sin que esto pueda considerarse como una discriminación. .

${ }^{68}$ OMAÑA PARÉS, Gustavo, "La Reforma de la Legislación Marítima Comercial de Venezuela", Foro de Derecho Mercantil N. ${ }^{\circ}$ 8, Legis Editores S.A., Bogotá, 2005, p. 137.

69 ... por disposición del artículo 51 de la Ley Orgánica del Trabajo, el "capitán de buque" ejerce funciones de dirección y administración, por tanto, funge como representante del patrono, en consecuencia, está obligado a garantizar el orden y la seguridad de sus tripulantes, pasajeros y carga. Dicha misión es relevante en atención a que el buque se encuentra navegando en diversas partes del mundo, razón por la que el "capitán" cumple funciones de control, supervisión y sanción sobre las persona que se hallan a bordo.
} 
norma. Tampoco es correcto discurrir que al estar sometido al control del armador su capacidad de decisión se socava y se cuestiona su carácter de empleado de dirección, pues todos estamos sometidos a límites en nuestra voluntad, por lo cual no es un elemento distintivo del empleado de dirección la falta de sujeción a ordenes de otros, usualmente el presidente o el Chief Executive Officer de una empresa está sujeto a las directrices del contrato social y de la junta directiva, ésta a su vez a los accionistas, estos a los constituyentes, y así sucesivamente siempre habrá algo o alguien sujetando a otro. La LOTTTT no habla de grados o planos de responsabilidad o participación, de tal modo que ser directivo no implica no estar sujeto a un poder superior o exento de todo control, de recibir y obedecer órdenes, en fin, que no se requiere un poder absoluto y no supervisado para ser trabajador de dirección, basta con que:

(1) Intervenga en toma de decisiones u orientaciones de la entidad de trabajo, o

(2) Represente al patrono frente a otros y lo sustituya en todo o parte de sus funciones.

\section{Consideraciones finales}

El capitán tiene un haz de facultades que le convierten en empleado de dirección. Cuando las ejerza será empleado de dirección, tenga o no la titulación adecuada, acceda o no al cargo de conformidad con la legislación y las autoridades acuáticas.

Se debe determinar el ejercicio efectivo de esas facultades conforme se ha explicado para dar cumplimiento al principio de la primacía de la realidad. Es un asunto netamente de hecho y de pruebas, lo que no existe en el expediente no existe para el juez. No debe confundirse el tener la facultad de modo efectivo con ejercerla pues la oportunidad para hacerla valer quizá no se haya presentado, por lo tanto la investigación del juez no debe limitarse a verificar que ejerciera las facultades sino que efectivamente las tuviera de modo tal que no pueda decirse que una facultad no existe como tal porque no la ejerció si el supuesto para su ejercicio no se realizó. Esta distinción es importante y es difícil encontrar referencias a ello.

Luego de ese cúmulo de facultades, cuando las ejerce de modo limitado, se presentará, ya el problema de derecho, de que cuál es la cantidad e intensidad necesaria de esas facultades que permitan calificarle como empleado de dirección o no porque son pocas o poco relevantes o significativamente castradas por el control del armador o empleador.

En el caso de que se determine que alguien ha desempeñado de facto el puesto de capitán, las consecuencias de la ilicitud de ese cargo, de ese desempeño, de espaldas a la normativa acuática, planean sobre la validez del contrato de trabajo y los efectos del desempeño de facto. Los casos conocidos de la jurisprudencia social se ciñen a desenmascarar simulaciones y aplicar lar normas laborales que detectan no aplicadas, fuera de eso las múltiples interrogantes que pueden surgir de esto quedan sin respuesta, la más importante es que si el ejercicio del cargo de capitán es ilícito ¿cómo se corrige y repara la vulneración del orden jurídico más allá de la condición y beneficios laborales del capitán? La LOTTT no aporta muchas luces sobre esto, tampoco la jurisprudencia social y la doctrina ha pasado de largo siempre en los casos de simulación de la relación laboral 
pareciendo contentarse con el análisis del haz de indicios que denota la laboralidad de la relación. ¿Quien responde por los daños causados por la ilicitud? ¿Puede el patrono despedir al falso capitán? ¿Es el contrato de trabajo nulo? ¿Es una falta subsanable? Sobre estos puntos hemos esbozado algunos caminos posibles y advertido sobre otros que no se han de andar. Jurisprudencia y doctrina también han fallado tratando la simulación de forma simplista, naif, ignorando, entre otros elementos relevantes de ese fenómeno complejo, la causa de la simulación e inadvertidamente presos de sesgos cognitivos sentencian y concluyen, normalmente de modo implícito, que el trabajador es víctima y el patrono autor intelectual. El análisis fundamental siempre ha de ser el mismo: incumplimiento/ilícito, daño, responsabilidad, reparación. La jurisprudencia reciente suele analizar y aplicar el primer y último punto ignorando el daño y la responsabilidad; la doctrina sigue los mismos derroteros.

Cuando se determine que la persona desarrolla en efecto funciones de capitán con intensidad y cantidad suficiente para calificarlo como empleado de dirección, tendrá un régimen laboral distinto frente a los trabajadores regulares principalmente en los siguientes aspectos:

I. Su cargo habrá de estar excluido del ámbito de una convención colectiva, no se aplican los beneficios de ésta pactados en favor de los trabajadores de menor rango, la jurisprudencia ha reiterado en múltiples oportunidades que sería contrario a la justicia y equidad permitirlo y exigirlo. Sobre el punto son consultables las sentencias de la Sala de Casación Social de fecha 11.08.2005, caso Shlumberger ${ }^{70}$ y del

70 Discurre la controversia, en torno, a si el trabajador demandante es acreedor o no de los beneficios consagrados en la Convención Colectiva Petrolera. Al respecto, es menester destacar su cláusula tercera, la cual expresa:

«Están cubiertos por esta Convención todos los trabajadores de la Empresa comprendidos en las denominadas Nómina Diaria y Nómina Mensual Menor; no así aquellos que realmente desempeñen los puestos o trabajos contemplados en los Artículos 42, 45, 47, 50 y 510 de la Ley Orgánica del Trabajo, que pertenecen a la categoría conocida en la Industria Petrolera como Nómina Mayor, quienes serán exceptuados de la aplicación de la presente Convención. No obstante esta excepción, los trabajadores de la Nómina Mayor no serán afectados en los derechos sindicales que les consagra la Ley Orgánica del Trabajo y su Reglamento.En este sentido, no podrán ser impedidos si esa fuere su voluntad, de participar en las actividades sindicales del Sindicato Petrolero en la región donde efectúan sus labores «.

Por otra parte, la mencionada cláusula tercera de la aludida Convención, excluye de su campo de aplicación, no solo a los empleados de dirección sino también a los de confianza, en el entendido que los empleados de la Nómina Mayor, poseen un conjunto de beneficios que superan los contemplados en la Convención, para los empleados de Nómina Diaria o Nómina Mensual.

Asimismo, está suficientemente acreditado en autos, que durante casi diez años que duró la relación laboral, el trabajador no reclamó los beneficios de la Nómina Diaria o Mensual, lo cual confirma que evidentemente percibía los de la Nómina Mayor, por lo que en este caso particular la Sala llega a la conclusión, que el trabajador estaba excluido del ámbito de aplicación subjetiva de la Convención Colectiva de Trabajo.

Reposa en actas del expediente, la Convención Colectiva Petrolera, y en virtud de ello, a la luz del principio iura novit curia, debe la Sala señalar, que en la referida Convención Colectiva, se encuentra plasmado como anexo $\mathrm{N}^{\circ}$ 1, el «tabulador único de nómina diaria«, y del examen de este instrumento, no se denota el cargo de representante de ventas, el cual señaló detentar el accionante para la fecha de término de la relación laboral.

En mérito de las anteriores consideraciones,sería contrario al principio de justicia y equidad, que habiendo percibido el trabajador los beneficios propios de la Nómina Mayor, pretenda percibir adicionalmente, aquellos previstos para la Nómina Diaria o Mensual.

Como corolario de lo anterior, al verificarse que el actor estaba exceptuado del ámbito de aplicación de la Convención Colectiva Petrolera, ninguna reclamación por diferencia salarial con sustento a ello puede ser 
26.07.2010, caso Flor María Castro ${ }^{71}$. El TSJ no deja mayores dudas, y no agrega mayores matices a las previsiones de la LOTTT, por lo que los trabajadores de nómina gerencial —y el capitán es el gerente de la nave-, los representantes del patrono, los empleados de dirección -y el capitán reúne en él todas estas características-, pueden ser excluidos del ámbito de una convención colectiva, y cuando ello sucede no puede exigir los beneficios derivados de ella.

II. No está sujeto al régimen de estabilidad. Un capitán es un empleado de dirección que representa al patrono y hace sus veces frente a terceros y a los trabajadores.

III. No está sometido a los límites de la jornada del trabajador ordinario, en este sentido puede verse la sentencia N. ${ }^{\circ} 1.183$ SC de 03.07.2001, caso Rodrigo Pérez Bravo y otro $^{72}$.

declarada procedente, y por lo tanto, las diferencias por prestaciones sociales e indemnizaciones calculadas con base a las mencionadas diferencias salariales, tampoco pueden prosperar..

${ }^{71}$ Cláusula $\mathrm{N}^{\circ} 2$

La presente Convención Colectiva de Trabajo se aplicará a todos los trabajadores obreros del Instituto Nacional de Cooperación Educativa (INCE) y a los demás trabajadores de las Asociaciones Civiles INCE e Institutos Sectoriales INCE, con excepción, de los Gerentes que ejerzan funciones de dirección o de confianza, conforme a las disposiciones de la Ley Orgánica del Trabajo. (Resaltado de la Sala).

Ahora bien, la recurrente ostentó en el Instituto Nacional de Cooperación Educativa (INCE), el cargo de Gerente de Recursos Humanos, hecho no controvertido por las partes, por lo que de acuerdo a lo establecido en la cláusula $\mathrm{N}^{\circ} 2$ del Contrato Colectivo de Trabajo, la demandante se encuentra excluida de los aumentos salariales contractuales, en consecuencia se declaran improcedentes los aumentos salariales contractuales reclamados por la demandante. Así se decide.

De la misma manera, la demandante reclama que las diferencias salariales adeudadas por la demandada deben incidir en los beneficios contemplados en el Contrato Colectivo de Trabajo, por lo tanto, reclama el pago de diferencias del bono de profesionalización, diferencia en el bono único, diferencia de prima por hijos menores de dieciocho (18) años, y el cumplimiento por parte del patrono de la cláusula $\mathrm{N}^{\circ} 10$ del Contrato Colectivo, no obstante, el artículo 2 del referido contrato contempla el ámbito de aplicación y excluye expresamente a los trabajadores que ostenten cargos de dirección y de confianza, por lo tanto no le es aplicable la normativa contemplada en el Contrato Colectivo de Trabajo, en virtud del cargo ostentado por la trabajadora, en consecuencia se declaran improcedentes las diferencias contractuales demandadas. Así se decide.

${ }^{72}$ En tal sentido, observa la Sala que la norma del artículo 198 de la Ley Orgánica del Trabajo, enumera aquellos trabajadores que en virtud de la naturaleza del servicio prestado, no están sometidos a las limitaciones establecidas en materia de jornada ordinaria de trabajo.

En efecto, se hace mención a los trabajadores de dirección y de confianza, quienes tienen el carácter de representantes del patrono, por lo que su desempeño evidentemente reviste un carácter especial, debido a la importante labor que deben cumplir en su lugar de trabajo y a las responsabilidades que conlleva su ejercicio, razón por la cual, resulta lógico que no estén sometidos a las limitaciones ordinarias que en cuanto a la jornada laboral ordinaria se establecen. Además, el artículo en comento, regula una jornada máxima a cumplir, cuando señala que "Los trabajadores a que se refiere este artículo no podrán permanecer más de once (11) horas diarias en su trabajo y tendrán derecho, dentro de esta jornada, a un descanso mínimo de una (1) hora", estableciéndose en ese sentido, un límite a la jornada que deben cumplir estos trabajadores. Por su parte, el resto de los trabajadores mencionados en el referido artículo, es decir, los de inspección y vigilancia "cuya labor no requiera un esfuerzo continuo", los que "desempeñan labores que requieran la sola presencia, o labores discontinuas o esencialmente intermitentes que implican largos períodos de inacción durante los cuales las personas que las ejecutan no tienen que desplegar actividad material ni atención sostenida, y sólo permanecen en sus puestos para responder a llamadas eventuales"; y los que "desempeñen funciones que por su naturaleza no están sometidos a jornada", son excluidos de la jornada ordinaria, con la misma regulación especial a la cual se hizo referencia supra, en virtud de que el trabajo desempeñado no está sometido a un horario fijo, ya que en algunas oportunidades la jornada cumplida es incluso menor a la prevista ordinariamente y además no requiere ningún esfuerzo físico e intelectual para su efectivo desarrollo, necesitándose sólo la presencia física, y pudiendo el trabajador incluso, en el mismo 


\section{Bibliografía}

ALEMANY YERN, Marcos. La responsabilidad del capitán del buque tras la implantación del código ISM. Trabajo final de carrera, presentado ante la Facultad Politécnica de Cataluña. 2005. Consultado en https://upcommons.upc.edu/bitstream/handle/2099.1/6358/Cap\%C3\%ADtulo\%202.pdf? ALFONSO GUZMÁN, Rafael. "Nueva Didáctica del Derecho del Trabajo”, Caracas, Editorial Melvin, 2004.

ÁLVAREZ LEDO, Tulio. "Derecho Marítimo”, Publicaciones UCAB, Caracas, 2011.

ARROYO, Ignacio y RUEDA MARTÍNEZ, José Alejo. "Compendio de Derecho Marítimo: (Ley 14/2014, de Navegación Marítima)", Editorial Tecnos, Madrid, 2020

DÍAZ DE LA ROSA, Angélica, "Los Contratos de Gestión de Tripulación de Buques: Crew Management Agreements", La Ley, Madrid, 2011,

MADURO LUYANDO, Eloy. "Curso de Obligaciones: Derecho Civil III”, Universidad Católica Andrés Bello, Caracas, 2009.

MARTÍNEZ, Patricia. "Los Sujetos de la Navegación en la nueva Ley de Comercio Marítimo" III Congreso de Derecho Marítimo, Asociación Venezolana de Derecho Marítimo. Caracas, 2004.

MARTÍNEZ MORENO, Carolina. "El Trabajo de Alta Dirección: Evolución Histórica y Fuentes de Regulación”, Revista Española de Derecho del Trabajo, N. ${ }^{\circ}$ 125, Civitas, 2005.

MONTOYA MELGAR, A. "Derecho del trabajo”, editorial Tecnos, Madrid, 2016.

OMAÑA PARÉS, Gustavo. "La Reforma de la Legislación Marítima comercial de Venezuela", Foro de Derecho Mercantil N. 8, Legis Editores S.A., Bogotá, 2005.

OMAÑA PARÉS, Gustavo. "Estudio del Régimen del Trabajo Marítimo en Venezuela", Editorial Jurídica Venezolana, Caracas, 2018.

POTHIER, Robert Joseph. "Tratado de las Obligaciones", Editorial Heliasta, Buenos Aires, 2007.

THIBIERGE, Catherine. "Nulidad, Restituciones y Responsabilidad", Universidad Externado de Colombia, Bogotá, 2010.

VRANKEN, Martin. "Death of Labor Law? Comparative Perspectives", Melbourne University Press. 2009.

sitio de trabajo -siempre y cuando no perturbe su ejercicio emplear su tiempo en otras actividades. (Destacado del fallo que hoy se dicta) 
(cc) EY-NC-SA 